\title{
Alternation of wet and dry sides during partial rootzone drying irrigation enhances leaf ethylene evolution
}

J.G. Pérez-Pérez ${ }^{1,2 *}$, J. Puertolas ${ }^{3}$, A. Albacete ${ }^{4}$ and I.C. Dodd ${ }^{3}$.

${ }^{1}$ Centro para el Desarrollo de la Agricultura Sostenible, Instituto Valenciano de Investigaciones Agrarias, Moncada-Valencia, Spain.

${ }^{2}$ Equipo de Riego y Fisiología del Estrés, Instituto Murciano de Investigación y Desarrollo Agrario y Alimentario, La Alberca - Murcia, Spain.

${ }^{3}$ Lancaster Environment Centre, University of Lancaster, LA1 4YQ, United Kingdom.

${ }^{4}$ Equipo de Horticultura y Agrotecnología. Instituto Murciano de Investigación y Desarrollo Agrario y Alimentario, La Alberca, Murcia, Spain.

* Corresponding author:

Centro para el Desarrollo de la Agricultura Sostenible

Instituto Valenciano de Investigaciones Agrarias

Moncada, 46013 (Valencia) Spain.

E-mail: perez_juaperb@gva.es

Running title: Soil moisture dynamics and ACC/ethylene signalling.

Keywords: ACC, ethylene, partial rootzone drying, root-to-shoot signalling, soil moisture heterogeneity.

\section{Statement}

Partial rootzone drying induces root $\mathrm{ABA}$ and $\mathrm{ACC}$ accumulation while re-watering dry soil increases leaf xylem ACC concentration and foliar ethylene evolution.

\section{Highlights}

- Partial rootzone drying and re-watering cause spatial changes in root water uptake

- Soil drying increased both root ABA and ACC accumulation

- Re-watering increased xylem / leaf ACC concentration and foliar ethylene evolution

- Re-watering increased leaf water use efficiency by transiently closing the stomata

- Stomatal conductance was best explained by leaf xylem ABA concentration 


\begin{abstract}
Soil drying increases endogenous $\mathrm{ABA}$ and $\mathrm{ACC}$ concentrations in planta, but how these compounds interact to regulate stomatal responses to soil drying and re-watering is still unclear. To determine the temporal dynamics and physiological significance of root, xylem and leaf $\mathrm{ABA}$ and $\mathrm{ACC}$ concentrations in response to deficit irrigation (DI) or partial rootzone drying (PRD-F) and re-watering, these variables were measured in plants exposed to similar whole pot soil water contents. Both DI and PRD-F plants received only a fraction of the irrigation supplied to well-watered (WW) plants, either to all (DI) or part (PRD-F) of the rootzone of plants grown in split-pots. Both DI and PRD-F induced partial stomatal closure, increased root $\mathrm{ABA}$ and $\mathrm{ACC}$ accumulation consistent with local soil water content, but did not affect xylem or leaf concentrations of these compounds compared to WW plants. Two hours after re-watering all (DI-RW) or part of the rootzone (PRD-A) to the same soil water content, stomatal conductance returned to WW values or further decreased respectively. Rewatering the whole rootzone had no effect on xylem and leaf ABA and ACC concentrations, while re-watering the dry side of the pot in PRD plants had no effect on xylem and leaf ABA concentrations but increased xylem and leaf ACC concentrations and leaf ethylene evolution. Leaf water potential was similar between all irrigation treatments, with stomatal conductance declining as xylem ABA concentrations and leaf ACC concentrations increased. Prior to rewatering PRD plants, accounting for the spatial differences in soil water uptake best explained variation in xylem ACC concentration suggesting root-to-shoot ACC signalling, but this model did not account for variation in xylem ACC concentration after re-watering the dry side of PRD plants. Thus local (foliar) and long-distance (root-to-shoot) variation in ACC status both seem important in regulating the temporal dynamics of foliar ethylene evolution in plants exposed to PRD.
\end{abstract}




\section{Introduction}

One of the most critical factors limiting crop yields is fresh water scarcity. Often insufficient irrigation resources and/or regulatory limitations on water abstraction mean that farmers apply irrigation volumes less than calculated crop evapotranspiration requirements, which is termed deficit irrigation (Fereres and Soriano 2007). The deficit irrigation technique of partial rootzone drying (PRD) aims to maintain crop water status by altering root-to-shoot chemical signalling to induce partial stomatal closure, thereby improving agricultural water use efficiency (Dry et al., 2000; Stoll et al., 2000; Kang and Zhang, 2004). In PRD plants, heterogeneous soil moisture is established by irrigating one part of the root system while the other part is allowed to dry. Drying part of the rootzone stimulates root ABA accumulation (Khalil and Grace, 1993; Stoll et al., 2000; Pérez-Pérez et al., 2018), some of which is xylem-transported to the shoot to partially close the stomata, restricting transpiration (Dodd, 2005). Typically, the irrigated and drying parts of the rootzone are regularly alternated. Soil drying and rewetting cycles during PRD stimulated root growth (Mingo et al., 2004; Pérez-Pérez et al., 2018), enhanced soil nutrient availability and plant nutrient uptake (Wang et al., 2010), and altered root-sourced chemical signalling to the shoots by transiently increasing leaf xylem ABA concentration, [X-ABA] leaf (Dodd et al., 2006; Romero et al., 2012). Thus increased crop yields of PRD plants compared with DI plants when irrigated at the same volumes (Dodd, 2009) may be partially attributed to the impacts of the drying and re-wetting cycles (that characterize alternate PRD) on root-to-shoot ABA signalling (Dodd et al., 2006) that affects stomatal conductance, photosynthesis and thus whole plant carbon gain.

However, crop performance can differ between irrigation techniques independent of changes in root-to-shoot ABA signalling. Thus, PRD increased crop water use efficiency of lemon (Citrus limon) compared to plants grown with conventional deficit irrigation, without any change in ABA signalling (Pérez-Pérez et al., 2012), suggesting that alternative mechanisms may be important. Furthermore, prolonged drying cycles during PRD may actually limit ABA transport from citrus roots (Pérez-Pérez et al., 2018), thereby decreasing xylem ABA concentration and potentially allowing higher photosynthesis, which may be more physiologically important than any transient pulse in xylem ABA concentration after alternating the wet and dry parts of the root system (Dodd et al., 2015). Stomata respond to many different signals, and much work has tried to establish both the identity and sources of these signals (Dodd, 2005; 
Rodriguez-Dominguez et al., 2016; Castro et al., 2019). Moreover, it is becoming increasingly evident that stomatal behaviour involves interactions between different hormonal signals (Acharya and Assman, 2009; Beguerisse-Diaz et al., 2012; Nazareno and Hernandez, 2017).

Soil drying and nutrient limitation can stimulate root biosynthesis of the ethylene precursor 1-aminocyclopropane-1-carboxylic acid (ACC), which is catalysed by ACC synthase (ACS). ACC can be converted to ethylene in the roots catalysed by ACC oxidase (ACO) or xylem-transported to the shoot (Tudela and Primo-Millo, 1992; Martinez-Andujar et al. 2016), which may partially close the stomata and limit vegetative growth. Transplanting bare-rooted mandarin (Citrus reshni) seedlings to dry sand for $24 \mathrm{~h}$, which decreased leaf water potential to -3.0 MPa, increased xylem ACC concentration (Tudela and Primo-Millo, 1992). A more moderate, relatively stable soil drying treatment (matric potential did not exceed - $0.25 \mathrm{MPa}$ ) of pea (Pisum sativum) roughly doubled xylem ACC concentration (Belimov et al., 2009). However, whether enhanced root-to-shoot ACC signalling stimulates leaf ethylene production of plants grown in drying soil is not clear, since soil drying can increase (Beltrano et al. 1999; Mayak et al., 2004; Zhang et al., 2018), have no effect on (Ibort et al., 2018) or even decrease (Morgan et al., 1990; Li et al., 2017) ethylene production. Temporal changes in drying and re-wetting, and the severity of soil drying, may explain this variation in ethylene response. Only when cotton (Gossypium hirsutum) seedlings were exposed to a restricted range of leaf water deficits did re-watering transiently enhance ethylene production (Morgan et al., 1990), whereas PRD (with daily irrigation of part of the rootzone) stimulated leaf ethylene production of tomato (Solanum lycopersicum) plants (Sobeih et al., 2004). Furthermore, soil drying may induce complex (and sometimes opposing) changes in expression of genes involved in the ethylene biosynthesis pathway (Ibort et al., 2018) and consequent enzyme activities (Andersen et al., 2004; Zhang et al., 2018), making it difficult to predict whether soil drying increases or decreases foliar ethylene evolution.

While it is generally accepted that ethylene is involved in regulating multiple physiological processes including fruit ripening, leaf and flower abscission, and inhibiting root and shoot growth, its role in stomatal regulation seems to be speciesdependent (Dodd, 2003; Pierik et al., 2006). Whereas high exogenous ethylene concentrations (60-70 ppb) caused stomatal closure of tomato (Madhavan et al., 1983), foliar sprays of the ethylene releasing chemical ethephon or the ethylene agonist 1-MCP 
induced stomatal opening or closure respectively in tomato (Arve and Torre, 2015). Although waterlogging stimulated xylem ACC concentration and root-to-shoot ACC transport of tomato prior to concurrent enhanced foliar ethylene evolution and stomatal closure (Bradford and Yang, 1980; Else et al. 1995), supplying detached leaves with 1$100 \mu \mathrm{M}$ ACC via the transpiration stream showed no significant stomatal response (Bradford and Hsiao, 1982) in spite of petiole epinasty (an ethylene-mediated effect). While xylem-supplied ACC (which stimulates leaf ethylene evolution) seems to have limited direct effects on stomatal conductance, ACC/ethylene may be important in modulating ABA-induced stomatal closure. Thus, ACC antagonised ABA-induced stomatal closure in Arabidopsis epidermal strips (Tanaka et al., 2005), and 1-MCP application restored soil drying-induced stomatal closure of aged wheat (Triticum aestivum) leaves (Chen et al., 2013). To what extent ethylene mediates stomatal responses of plants exposed to partial rootzone drying has received little attention, even though PRD can enhance ethylene evolution of tomato leaves (Sobeih et al., 2004) and fruit (Haghighi et al., 2013).

To date, almost all investigations of root-to-shoot signalling in plants exposed to PRD have focused on the dynamics of ABA signalling during soil drying and re-wetting cycles, since increased ABA status is correlated with enhanced leaf water use efficiency (Thompson et al., 2007). Soil drying stimulated root ABA accumulation in the dry part of the rootzone (Khalil and Grace, 1993; Stoll et al., 2000; Pérez-Pérez et al., 2018), but also restricted sap flow from these roots (Dodd et al., 2008a; b), thus alternating the wet and dry parts of the rootzone was needed to maintain root-to-shoot ABA signalling (Dodd et al., 2006; Pérez-Pérez and Dodd, 2015). Whether similar changes occur in plant ACC status is not known. To understand the temporal and spatial regulation of ethylene synthesis in plants exposed to PRD and conventional deficit irrigation, and after re-watering, multiple ethylene-related variables (root, xylem sap and leaf ACC concentrations, foliar ACO activity and ethylene evolution) were measured. Consequently, we hypothesised that PRD also affected stomatal responses by modulating leaf ethylene evolution, which was regulated by changes in root ACC accumulation, root-to-shoot ACC signalling and foliar ACO activity, and/or by interacting with ABA. 


\section{Materials and Methods}

Tomato (Solanum lycopersicum Mill. cv. Ailsa Craig) plants were grown with their roots split between two compartments as previously described (Pérez-Pérez and Dodd, 2015). Plants were raised in a single walk-in controlled environment room $(3 \times 4$ $\mathrm{m})$ at the Lancaster Environment Centre under a $9 \mathrm{~h}$ photoperiod (08:30-17:30h), consistent with our previous work (Pérez-Pérez and Dodd, 2015). Day-night variation caused fluctuations in temperature $\left(16-26^{\circ} \mathrm{C}\right)$ and atmospheric evaporative demand (0.2$1.2 \mathrm{kPa}$ ). Metal halide lamps (HQIT $400 \mathrm{~N}$, Osram, St Helens UK) were $1.2 \mathrm{~m}$ above bench height and provided $220 \mu \mathrm{mol} \mathrm{m} \mathrm{m}^{-2} \mathrm{~s}^{-1}$ photosynthetic photon flux density (PPFD) at bench height.

Several batches of tomato plants were produced as described above. Experiment 1 aimed to define relationships between root $\mathrm{ABA}$ concentration ([ABA]root) and root ACC concentration ([ACC $\left.]_{\text {root }}\right)$ and soil water content. Eight weeks after seeds were planted, different irrigation treatments were applied by withholding irrigation from the entire pot (homogeneous deficit irrigation - DI) or half of it (heterogeneous irrigation PRD). To generate a range of whole pot soil water contents, water was withheld from well-watered plants for varying lengths of time (12-36 h), but all plants (13 for PRD and 15 for DI) were sampled on the same day (between 10:00 $\mathrm{h}$ and 14:00h).

Experiment 2 utilised 6 batches of tomato plants to analyse the influence of rewatering DI and PRD plants that had been exposed to drying soil. This experiment imposed 5 irrigation treatments: well-watered (WW), deficit irrigated (DI), fixed partial rootzone drying (PRD-F) which dried part of the pot while the other part remained wellwatered, DI re-watered (DI-RW) which dried and re-watered all of the pot surface, and alternate PRD (PRD-A) which dried and re-watered part of the pot (Fig. 1). To quantify the fractional soil water uptake from each compartment in these experiments (each comprising five plants per batch, one for each irrigation treatment), two theta probes (Model ML2X, Delta-T Devices, Burwell, UK) were placed vertically into the top of each soil compartment to estimate gravimetric soil water content $\left(\theta_{g}-\right.$ see Supplementary Fig. 1). The slope of soil moisture decline was used to calculate water uptake as previously described (Pérez-Pérez and Dodd, 2015). DI and PRD-F plants were sampled at the same whole pot soil moisture level (when water uptake from the dry side of PRD plants ceased). Based on our previous work (Pérez-Pérez and Dodd, 2015), the sampling time in re-watered/alternated plants was optimised to detect treatment differences in root-to-shoot chemical signals. Thus, DI-RW and PRD-A 
plants were sampled 2 hours after re-watering/alternation (when water uptake from the re-watered side occurred, with soil moisture high in both DI-RW and PRD-A plants to minimise the influence of the next drying cycle). Leaf gas exchange, leaf water potential ( $\Psi_{\text {leaf }}$ ) and xylem sap ABA and ACC concentration were measured in Leaf 7 (numbering from the base of the plant). The remaining measurements (leaf ACC and ABA concentration, leaf ethylene production and leaf ACC oxidase activity) utilised Leaf 6. Roots of different diameters were collected from inside the soil mass at different depths from each side of the pot, in trying to gain a representative sample of the whole root system in WW, DI and DI-RW plants and a representative sample from each side of the pot in PRD-F and PRD-A plants. In each compartment of the pot, soil (including roots) was carefully removed from the pot, weighed and then oven dried to determine whole pot soil water content $\left(\theta_{\text {pot }}\right)$.

\section{Physiological measurements}

Single leaf gas exchange (in Leaf 7) was determined using an infrared gas analysis (Li-COR 6400X, Lincoln, NE, USA). The air flow rate inside the leaf chamber was $400 \mu \mathrm{mol} \mathrm{s}{ }^{-1}$. The temperature of the block of the leaf chamber was $26^{\circ} \mathrm{C}$. The humidity was controlled manually, by adjusting the flow of air through the desiccant, to avoid excessive humidity in the leaf chamber. Portable 12-g cartridges of high-pressure, liquefied, pure $\mathrm{CO}_{2}$ were attached to the console by an external $\mathrm{CO}_{2}$ source assembly and were controlled automatically by a $\mathrm{CO}_{2}$ injector system (6400-01 LiCOR, Lincoln, Nebraska, USA). The reference $\mathrm{CO}_{2}$ concentration was fixed at $400 \mu \mathrm{mol} \mathrm{mol}^{-1}$. All measurements were made using a red-blue light source (6400-02B light emitting diode; Li-COR, Lincoln, Nebraska, USA) attached to the leaf chamber. The PPFD was fixed at $400 \mu \mathrm{mol} \mathrm{m} \mathrm{m}^{-2} \mathrm{~s}^{-1}$, which corresponded to the PPFD at the height of Leaf 7. Leaves were allowed to equilibrate to these conditions for $3 \mathrm{~min}$ before data were recorded.

$\Psi_{\text {leaf }}$ of the same leaf (Leaf 7) was measured using a Schölander type pressure chamber (Plant Moisture Systems, Santa Barbara, CA, USA), then an overpressure (0.4 $\mathrm{MPa}$ ) applied to the leaf (the same overpressure to all plants) to express xylem sap, which was collected in a pre-weighed eppendorf tube and frozen in liquid nitrogen, for later determination of $\mathrm{ABA}$ and $\mathrm{ACC}$ concentration. Previous work indicated no significant effect of the overpressure applied ( 0.1 versus $0.4 \mathrm{MPa})$ on xylem $\mathrm{ABA}$ concentration of tomato leaves (Dodd et al., 2009), so the higher pressure was utilised to provide sufficient sap for analysis. 
Leaf ethylene evolution was determined by placing detached leaflets from Leaf 6 ( $0.5 \mathrm{~g}$ of fresh weight) in $24 \mathrm{~cm}^{3}$ glass boiling tubes containing $5 \mathrm{~cm}^{2}$ of filter paper saturated with water. Each tube as flushed with air for $1 \mathrm{~min}$ prior to closure with a Suba-Seal (SLS, Nottingham, UK), and then incubated under $200 \mu \mathrm{mol} \mathrm{m}{ }^{-2} \mathrm{~s}^{-1}$ PPFD for 80 minutes. Using a disposable plastic syringe, a $1 \mathrm{~mL}$ headspace sample was withdrawn and stored in a $20 \mathrm{~mL}$ amber crystal vial, and sealed with a PP screw cap with central septum (membrane of $3.2 \mathrm{~mm}$ Silicone/PTFE). Ethylene was quantified by an ETD-300 photoacoustic laser spectrophotometer (Sensor Sense, The Netherlands). Preliminary experiments showed stable ethylene rates within 80 min of leaf detachment, suggesting limited wound-induced ethylene production.

Leaf and root samples for ABA determination were freeze-dried and finely ground. Deionized water was added at 1:50 weight ratio. Leaf and root extracts and sap samples were analysed by a radioimmunoassay (Quarrie et al., 1988), using the monoclonal antibody AFRC MAC 252 (kindly provided by Dr G Butcher, Babraham Bioscience Technologies, Cambridge, UK).

Leaf and root ACC concentrations were determined by the indirect method of Lizada and Yang (1979) and optimized by Bulens et al. (2011) as this technique was cheaper than HPLC-MS technology. Lyophilized leaf and root tissue were ground and $100 \mathrm{mg}$ was transferred to a $2 \mathrm{~mL}$ tube for extraction with $1.5 \mathrm{~mL}$ of sulfosalicylic acid $(5 \% \mathrm{v} / \mathrm{v})$. The tube was gently shaken at $4^{\circ} \mathrm{C}$ for $1 \mathrm{~h}$ and then centrifuged for $10 \mathrm{~min}$ at $3,090 \mathrm{~g}$ in a pre-cooled centrifuge at $4^{\circ} \mathrm{C}$. The supernatant was removed and used as the sample for the subsequent analysis. $600 \mu \mathrm{L}$ of sample was added to $200 \mu \mathrm{L}$ of distilled water and $160 \mu \mathrm{L}$ of $\mathrm{HgCl}_{2}(10 \mathrm{mM})$ in a $4 \mathrm{~mL}$ amber crystal vial. Immediately, the vial was sealed with a cap containing a septum. $400 \mu \mathrm{L}$ of cold $\mathrm{NaOH}$ (saturated) and $\mathrm{NaOCl}(5 \% \mathrm{v} / \mathrm{v})$ mixture $(2: 1, \mathrm{v} / \mathrm{v})$ was injected into the vial and the sample was incubated for $4 \mathrm{~min}$ on ice. After that, $1 \mathrm{~mL}$ of the headspace was removed and stored in a $20 \mathrm{~mL}$ amber crystal vial with a PP screw cap with central septum (membrane of 3.2 $\mathrm{mm}$ Silicone/PTFE). A standard curve was also made using different aliquots $(0,50$, 150,300 and $600 \mu \mathrm{L}$ ) of $2 \mu \mathrm{M}$ ACC standard solution. Ethylene produced was quantified by an ETD-300 photo-acoustic ethylene detector (Sensor Sense, The Netherlands).

As xylem sap ACC levels were below the limit of the detection by the indirect method described above, leaf xylem sap ACC concentration was analysed by HPLC/MS as previously described (Albacete et al., 2008) with some modifications. Xylem sap 
$(100 \mu \mathrm{L})$ was filtered through 13-mm-diameter Millex filters with $0.22 \mathrm{~mm}$ pore size nylon membrane (Millipore, Bedford, MA, USA) and $10 \mu \mathrm{L}$ of filtered sap injected in a U-HPLC-MS system consisting of an Accela Series U-HPLC (ThermoFisher Scientific, Waltham, MA, USA) coupled to an Exactive mass spectrometer (ThermoFisher Scientific, Waltham, MA, USA) using a heated electrospray ionization (HESI) interface. Mass spectra were obtained using the Xcalibur software version 2.2 (ThermoFisher Scientific, Waltham, MA, USA). For quantification of ACC, a calibration curve was constructed $\left(1,10,50\right.$, and $\left.100 \mu \mathrm{g} \mathrm{L}^{-1}\right)$ and corrected for $10 \mu \mathrm{g} \mathrm{L}^{-1}$ deuterated internal standard. Recovery percentages ranged between 92 and 95\%.

Leaf ACC oxidase (ACO) activity was determined by the method of Bulens et al. (2011), with some slight modifications allowing easier processing of material. Fresh leaf tissue was ground in liquid nitrogen to a fine powder with a pestle and mortar and $500 \mathrm{mg}$ was transferred to a $2 \mathrm{~mL}$ tube for extraction with $50 \mathrm{mg}$ of polyvinylpolypyrrolidone and $1 \mathrm{~mL}$ of a buffer consisting of $100 \mathrm{mM}$ Tris- $\mathrm{Cl}(\mathrm{pH}$ 7.2), $30 \mathrm{mM}$ sodium ascorbate and 10\% (v/v) glycerol. The tube was briefly shaken and then centrifuged at $22,000 \mathrm{~g}$ for 30 minutes. The supernatant was removed and used as the sample for the subsequent analysis. $400 \mu \mathrm{L}$ of the enzyme supernatant was added to 3.6 $\mathrm{mL}$ of an incubation buffer containing $100 \mathrm{mM}$ Tris- $\mathrm{Cl}(\mathrm{pH} 7.2), 5 \mathrm{mM}$ sodium ascorbate and 10\% (v/v) glycerol), $1 \mathrm{mM} \mathrm{ACC,} 0.02 \mathrm{mM} \mathrm{FeSO}_{4}, 20 \mathrm{mM} \mathrm{NaHCO} 3$ and $1 \mathrm{mM}$ dithiothreitol. The reaction was allowed to progress at $30^{\circ} \mathrm{C}$ for $1 \mathrm{~h}$ in the dark. After this period, $1 \mathrm{~mL}$ of the headspace was removed and stored in $20 \mathrm{~mL}$ amber crystal vials with a PP screw cap with central septum (membrane of $3.2 \mathrm{~mm}$ Silicone/PTFE). Ethylene was quantified by an ETD-300 photo-acoustic ethylene detector (Sensor Sense, The Netherlands).

In attempting to understand the variation in $[\mathrm{X}-\mathrm{ACC}]_{\text {leaf }}$ generated in response to fixed and alternate PRD, measured [X-ACC] leaf was compared with the $[\mathrm{X}-\mathrm{ACC}]$ predicted from two models where:

(i) $[\mathrm{X}-\mathrm{ACC}]_{\text {leaf }}$ depended only on whole pot soil water content, $\theta_{\text {pot }}$ (as in Fig. 3B) using the relationship:

$$
[\mathrm{X}-\mathrm{ACC}]_{\text {leaf }}=-0.59+0.45 \theta_{\text {pot. }}{ }^{-1}
$$


(ii) $[\mathrm{X}-\mathrm{ACC}]_{\text {leaf }}$ depended on $\theta_{\mathrm{g}}$ of each compartment of the split-pot, which affected both $[\mathrm{X}-\mathrm{ACC}]_{\text {root }}$ emanating from, and soil water uptake by, roots in those compartments, according to a simple model (Dodd et al. 2008a).

$$
[\mathrm{X}-\mathrm{ACC}]_{\text {leaf }}=\mathrm{F}_{\mathrm{wet}}[\mathrm{X}-\mathrm{ACC}]_{\text {root-wet }}+\mathrm{F}_{\text {dry }}[\mathrm{X}-\mathrm{ACC}]_{\text {root-dry }}
$$

(Equation 2)

where $F_{w e t}$ and $F_{\text {dry }}$ represent the fractions of the sap flow from the wet and dry compartments of the split-pot. Since xylem sap was collected only from leaves in this study, $[\mathrm{X}-\mathrm{ACC}]_{\text {root-wet }}$ and $[\mathrm{X}-\mathrm{ACC}]_{\mathrm{root}-\mathrm{dry}}$ were simulated using Equation 1, by assuming no change in $[\mathrm{X}-\mathrm{ACC}]$ in transit between roots and shoots and considering $\theta_{\mathrm{g}}$ of the wet or dry sides of the pot according to Pérez-Pérez and Dodd (2015).

\section{Statistical analysis}

Whole plant data were subjected to one-way analysis of variance (ANOVA) (Statsgraphics Centurion XV statistical package; Statpoint Technologies Inc., Warrenton, VA, USA), with the five irrigation treatments (WW, DI, PRD-F, DI-RW and PRD-A). When there was a significant difference $(P$-value $<0.05)$, means were separated using Tukey's multiple range test. In Experiment 1, relationships between soil and plant variables were fitted to linear and non-linear regressions using the data of DI and PRD-F plants. In Experiment 2, relationships between soil and plant variables were fitted to non-linear regressions by combining the data of all treatments. Two-way ANOVA was used to compare the effects of irrigation placement (PRD and DI) and rewatering on physiological responses and hormone concentrations.

\section{RESULTS}

\section{Physiological responses to soil drying}

To determine root tissue and xylem sap $\mathrm{ABA}$ and $\mathrm{ACC}$ responses to changes in soil moisture, 15 homogeneously irrigated (DI) plants and 13 heterogeneously irrigated (PRD) plants were sampled in Experiment 1 at different times (12 to $36 \mathrm{~h}$ ) after imposing the treatments. Withholding irrigation from the entire rootzone, or half of it, decreased soil moisture in the whole pot of DI plants and in the non-irrigated side of PRD plants (Fig. 1). To compare physiological responses in both irrigation treatments at the same whole pot soil water content $\left(\theta_{\text {pot }}\right)$, plants were sampled between a $\theta_{\text {pot }}$ range of 0.24 and $0.34 \mathrm{~g} \mathrm{~g}^{-1}$, which ensured high $\theta_{\mathrm{g}}$ values $\left(>0.34 \mathrm{~g} \mathrm{~g}^{-1}\right)$ in the wet side of PRD plants. In PRD plants, irrigation was suspended from the dry side of the pot for up to 36 
hours (until water-uptake ceased, while $\theta_{\mathrm{g}}$ in the wet side was maintained higher than $0.3 \mathrm{~g} \mathrm{~g}^{-1}$ ) (Fig. 1B, D). Water uptake from the dry side started to decrease when $\theta_{\text {dry }}<$ $0.25 \mathrm{~g} \mathrm{~g}^{-1}$, whereas at the same time plant water uptake increased in the wet side. In DI plants, irrigation was withheld at the beginning of the second photoperiod until $\theta_{\text {pot }}$ reached similar values as PRD plants $\left(\approx 0.28 \mathrm{~g} \mathrm{~g}^{-1}\right)$ (Fig. 1; Table 1). Compared to the WW and DI treatments, PRD significantly decreased whole plant water uptake by $37 \%$ and $25 \%$ respectively (Table 1$)$. Although stomatal conductance $\left(g_{s}\right)$ and photosynthesis $(A)$ were statistically similar between all treatments, again the values decreased in the order: WW > DI > PRD-F plants (Table 1). There were no significant differences in $\Psi_{\text {leaf }}$ and intrinsic water use efficiency $\left(A / g_{s}\right)$ across all treatments. Thus moderate soil drying limited whole plant water uptake when water was withheld from part of the rootzone (PRD plants), without significantly affecting leaf physiological responses.

Root ABA concentration ([ABA $]_{\text {root }}$ ) (Fig. 2A) and root ACC concentration ([ACC $]_{\text {root }}$ (Fig. 2B) increased exponentially as local soil water content decreased, with a single relationship irrespective of whether roots were sampled from PRD or DI plants. $[\mathrm{ABA}]_{\mathrm{root}}$ and $[\mathrm{ACC}]_{\text {root }}$ were maintained at basal levels with $\theta>0.26 \mathrm{~g} \mathrm{~g}^{-1}$, but both $[\mathrm{ABA}]_{\mathrm{root}}$ and $[\mathrm{ACC}]_{\mathrm{root}}$ increased as soil moisture declined. Comparing the slopes of each curve, $[\mathrm{ABA}]_{\mathrm{root}}$ was more responsive to soil water deficit than $[\mathrm{ACC}]_{\mathrm{root}}$ in the studied soil moisture range.

Although $[\mathrm{X}-\mathrm{ABA}]_{\text {leaf }}$ was not correlated with $\theta_{\text {pot }}$ in either irrigation treatment (Fig. 3A), the response of [X-ACC] $]_{\text {leaf }}$ to soil drying differed between DI and PRD-F treatments. In DI plants, [X-ACC $]_{\text {leaf }}$ increased linearly as $\theta_{\text {pot }}$ decreased, whereas in PRD plants was not correlated with $\theta_{\text {pot }}$ (Fig. 3B). High values of [X-ACC] leaf $(10$-fold higher than basal levels) were detected in some PRD plants when $\theta_{\text {pot }}$ decreased below $0.3 \mathrm{~g} \mathrm{~g}^{-1}$ (Fig. 3B), but this putative peak decreased progressively as less water was extracted from the dry side of the pot (Fig. 3C). When water uptake from the dry side ceased (Fig. 3C), [X-ACC] leaf returned to basal levels. Thus xylem ACC concentration, but not xylem ABA concentration, seemed related to the spatial distribution of water uptake in PRD plants.

\section{Physiological responses to re-watering}

Having established the impacts of PRD-F and DI treatments on soil moisture and xylem and root ABA and ACC concentrations, Experiment 2 (in a different group of plants) also examined the impacts of re-watering. Having imposed PRD-F until water 
uptake from the dry side of the pot ceased, this soil was fully re-watered $\left(\theta_{\mathrm{g}} \approx 0.45 \mathrm{~g} \mathrm{~g}^{-}\right.$ $\left.{ }^{1}\right)$ while water was withheld from the previously irrigated side. After this alternation, plant water uptake from the previous dry side was rapidly restored, while it decreased in the newly drying side (Fig. 1D). At the same time, DI plants were re-watered to a similar soil moisture level as WW plants, restoring plant water uptake to initial levels (Fig. 1C). Thus, water uptake responded rapidly to changes in soil moisture.

Although a similar $\theta_{\text {pot }}$ was reached in both DI and PRD-F treatments (Table 2), soil moisture distribution differed. In PRD-F plants, soil moisture was clearly heterogeneous with $\theta_{\mathrm{g}}$ of the wet side of the pot similar to WW plants, while $\theta_{\mathrm{g}}$ of the dry side decreased until $0.19 \mathrm{~g} \mathrm{~g}^{-1}$ (Fig. 4C). DI and PRD-F treatments decreased whole plant water uptake similarly by about $30 \%$ (Table 2), slightly (but not significantly) decreased stomatal conductance $\left(g_{s}\right)$ by $17 \%$ (Table 2), but maintained $\Psi_{\text {leaf }}$ and intrinsic water use efficiency $\left(A / g_{s}\right)$ compared with WW plants. After rewatering/alternation, $\theta_{\text {pot }}$ of DI-RW plants and the $\theta_{\mathrm{g}}$ of the newly irrigated side of the pot of PRD-A plants were similar to WW plants, but $\theta_{\mathrm{g}}$ of the newly drying side of the pot of PRD-A plants decreased significantly (0.29 $\left.\mathrm{g} \mathrm{g}^{-1}\right)$ (Fig. 4C). Re-watering reestablished whole plant water uptake and $g_{s}$ in DI-RW plants to similar levels as WW plants, without altering water use efficiency, $A / g_{s}$ (Table 2). In PRD-A plants, alternating the wet and dry sides partially recovered plant water uptake (Table 2), but $g_{s}$ decreased more than in PRD-F plants and was significantly (48\%) lower than WW plants (Table 2). Thus, water use efficiency of PRD-A plants increased compared to all other treatments (Table 2). Although re-watering did not change $\Psi_{\text {leaf, }}$ it induced transient stomatal closure (no more than 3 hours - Perez-Perez and Dodd, 2015) in PRD-A plants (Table 2).

Compared to WW plants, DI slightly but not significantly increased $[\mathrm{ABA}]_{\mathrm{root}}$ (1.8-fold higher) but had no significant effect on [ACC]root (Fig. 4A, B). In PRD-F plants, $[\mathrm{ABA}]_{\mathrm{root}}$ and $[\mathrm{ACC}]_{\text {root }}$ in the wet side of the pot were equivalent to $\mathrm{WW}$ values, but were higher (3-fold and 1.4-fold respectively) in the dry side of the pot (Fig. 4A, B). Re-watering restored $[\mathrm{ABA}]_{\text {root }}$ to similar levels as WW plants in DI-RW plants, but there were no statistically significant changes in $[\mathrm{ABA}]_{\mathrm{root}} 2$ hours after PRD alternation: roots in the re-irrigated soil still had high $[\mathrm{ABA}]_{\mathrm{root}}$ while those in newly drying soil had not yet accumulated any additional ABA (Fig. 4A). Alternating irrigation between the wet and dry sides in PRD-A plants increased [ACC] $]_{\text {root }}$ in the newly drying side of the pot and maintained high $[\mathrm{ACC}]_{\mathrm{root}}$ in the previously dry side 
(Fig. 4B). Thus root ACC concentrations in different parts of the pot responded more rapidly to PRD alternation than root $\mathrm{ABA}$ concentrations.

Re-watering/alternation did not alter $[\mathrm{X}-\mathrm{ABA}]_{\text {leaf }}$ in DI-RW plants compared with DI plants, but tended to increase $[\mathrm{X}-\mathrm{ABA}]_{\text {leaf }}$ in PRD-A plants by $38 \%$ (compared with PRD-F plants) (Fig. 5A). Leaf ABA concentration ([ABA]leaf) was not altered by the different irrigation treatments compared to WW plants (Fig. 5B). Thus xylem ABA concentration was more responsive to re-watering than leaf ABA concentration.

Compared with WW plants, DI and PRD-F had no significant effect on [XACC $]_{\text {leaf }}$ (Fig. 5C). In PRD-F plants, predicting [X-ACC $]_{\text {leaf }}$ based on $\theta_{\text {pot }}$ (Equation 1) overestimated its value by $28 \%$ (Table 3 ). However, multiplying the fraction of soil water uptake from each compartment by predicted [X-ACC $]_{\text {root }}$ based on its $\theta_{\mathrm{g}}$, and summing these terms (Equation 2), underestimated [X-ACC] leaf by only 7\% (Table 3). Re-watering/alternation only significantly increased [X-ACC] $]_{\text {leaf }}$ in PRD-A (7-fold more than PRD-F plants) (Fig. 5C). In PRD-A plants, predicting [X-ACC]leaf based on either whole pot $\theta$ (Equation 1) or multiplying the fraction of soil water uptake from each compartment by predicted $[\mathrm{X}-\mathrm{ACC}]_{\mathrm{root}}$ based on its $\theta_{\mathrm{g}}$, and summing these terms (Equation 2) underestimated its value by $44 \%$ and $43 \%$, respectively (Table 3 ). Leaf ACC concentration ([ACC $]_{\text {leaf }}$ ) did not differ between WW, DI, PRD-F and DI-RW treatments, but increased 4-fold in PRD-A plants compared to all other treatments (Fig. 5D). Generally, both leaf and xylem ACC concentrations were similarly responsive to re-watering, with both more responsive than ABA concentrations.

Leaf ACC oxidase activity (ACO) was similar in WW, DI and PRD-F plants (Fig. 5F). While re-watering/alternation seemed to increase ACO by approximately $30 \%$, no significant response of ACO to re-watering (Supplementary Table 1) was detected due to high treatment variability (Fig. 5F).

Across all treatments, WW plants had the highest ethylene evolution at 184 pmol $\mathrm{g}^{-1} \mathrm{FW} \mathrm{h}^{-1}$ (Fig. 5E). After omitting these WW plants, two-way ANOVA of the remaining treatments showed that PRD plants (PRD-F and PRD-A) had higher leaf ethylene evolution $(P$-value $=0.045)$ than DI plants (DI and DI-RW) by $43 \%$ (Supplementary Table 1). Furthermore, re-watering/alternation stimulated leaf ethylene production in both DI-RW and PRD-A treatments by $77 \%$ compared to DI and PRD-F treatments $($ Fig. 5E) $(P$-value $=0.044)$. Re-watering and irrigation placement factors did not interact $(P$-value $=0.51)$. Since absolute leaf ethylene evolution can be affected by the stomatal aperture, and the irrigation treatments altered $g_{s}$ (Table 2), leaf ethylene 
data was normalized according to stomatal conductance (leaf $\mathrm{C}_{2} \mathrm{H}_{4} / g_{s}$ ) (Fig. 6). After normalising, leaf ethylene evolution was statistically similar in WW, DI, PRD-F and DI-RW treatments, but was increased 4.2-fold in PRD-A plants (Fig. 6). Thus, PRD stimulated ethylene evolution, especially following alternation.

As the soil dried, leaf ethylene evolution decreased linearly with $\theta_{\text {pot }}\left(R^{2}=0.15\right)$ and leaf water potential $\left(\mathrm{R}^{2}=0.25\right)$, similarly in all treatments (Fig. 7A, B). Leaf ethylene evolution increased as $[\mathrm{ACC}]_{\text {leaf }}\left(\mathrm{R}^{2}=0.31\right)$, and leaf $\mathrm{ACO}$ activity $\left(\mathrm{R}^{2}=0.21\right)$ increased, again similarly in all irrigation treatments (Fig. 7C, D). Leaf ACC concentration significantly increased as $[\mathrm{X}-\mathrm{ACC}]_{\text {leaf }}\left(\mathrm{R}^{2}=0.87\right)($ Fig. 7E) and leaf ACO $\left(\mathrm{R}^{2}=0.30\right)$ (Fig. 7F) increased. Thus, both soil and leaf water status altered ethylene evolution by affecting foliar accumulation of its precursor ACC and its conversion.

Although $g_{s}$ was not related to whole pot soil water content (Fig. 8A), leaf water potential (Fig. 8B), [X-ACC] $]_{\text {leaf }}$ (Fig. 8D) and leaf ethylene evolution (Fig. 8F), it decreased exponentially as $[\mathrm{X}-\mathrm{ABA}]_{\text {leaf }}\left(\mathrm{R}^{2}=0.43\right)($ Fig. $8 \mathrm{C})$ and $[\mathrm{ACC}]_{\text {leaf }}\left(\mathrm{R}^{2}=0.35\right)$ (Fig. 8E) increased. Calculating different hormone ratios of xylem ([X-ABA] leaf / [X$\mathrm{ACC}]_{\text {leaf }}$ ) and leaf (ABA/ethylene) concentrations did not explain more of the variation in stomatal conductance (Supplementary Table 2). Thus, leaf xylem ABA concentration best accounted for variation in stomatal conductance.

\section{DISCUSSION}

While the effects of soil drying on root ABA accumulation are well-known (Fig. 2A here), few studies have measured root ACC concentration in response to drying soil per se (Tudela and PrimoMillo, 1992; Zhang et al., 2018) rather than saline (Albacete et al., 2008) or osmotic (Barnawal et al., 2017) stress. Although PRD stimulated leaf ethylene evolution (Sobeih et al., 2004), it was not clear whether this was due to local processes in the leaves and/or enhanced root-to-shoot ACC signalling (Else and Jackson, 2008). During PRD, both decreased soil matric potential (in the dry part of the rootzone) or oxygen availability (in the wet part of the rootzone) could increase root ACC concentration. Independent of the irrigation treatment imposed (PRD or DI), root ACC concentration increased linearly as the soil dried (Fig. 2B). At the maximum soil moisture $\left(0.40 \mathrm{~g} \mathrm{~g}^{-1}\right)$ experienced, ACC did not accumulate in the roots and, thus, it is unlikely that the plants were overwatered (Fiebig and Dodd, 2016) even if leaf ethylene evolution was highest in WW plants (Fig. 5E). That root ACC accumulation (lowest) was decoupled from leaf ethylene evolution (highest) in WW plants does not support 
the concept of root-to-shoot ACC signalling, suggesting considerable local regulation of ethylene evolution (discussed later). However, the ethylene relations of plants (Figs 2B, 3B, 5C-F) exposed to drying and re-wetting cycles emphasises the importance of root hormone accumulation and its export to the shoot.

In PRD-F plants, leaf xylem ACC concentration was highest between 0.28-0.32 $\mathrm{g} \mathrm{g}^{-1}$ whole pot soil water content (Fig. 3B), with divergent soil moisture contents in wet (0.33-0.37 $\left.\mathrm{g} \mathrm{g}^{-1}\right)$ and dry $\left(0.20-0.28 \mathrm{~g} \mathrm{~g}^{-1}\right)$ parts of the rootzone. Root ACC concentration at $0.24 \mathrm{~g} \mathrm{~g}^{-1}$ was $30 \%$ higher than at $0.35 \mathrm{~g} \mathrm{~g}^{-1}$ (Fig. 2B). Nevertheless, with continued soil drying, xylem ACC concentration of PRD-F plants did not differ from DI plants (Fig. 3B), presumably because sampling occurred when roots in drying soil contributed little to the transpiration stream (Fig. 3C). At this time, [X-ACC] leaf was best predicted with a model that accounted for the water-uptake fractions from each part of the root system (Table 3). Similarly, prolonged soil drying did not enhance leaf xylem ABA concentration of PRD plants (Dodd et al., 2008a). Re-watering the dry part of the rootzone was necessary to increase sap flow from these roots (Fig. 1 here; PérezPérez and Dodd, 2015) and root-to-shoot ABA signalling (Dodd et al., 2006) and substantially increase leaf xylem ACC concentration (Fig. 5C). However, at this time, the model substantially underestimated $[\mathrm{X}-\mathrm{ACC}]_{\text {leaf }}$ (Table 3). Since re-watering the dry side of the rootzone re-established sap flow from those roots (Fig. 1D), ACC accumulated in those roots could be remobilised and transported via the xylem to the shoot. Leaf ACC concentration (Fig. 5D) and ethylene evolution (Fig. 5E) was also substantially increased in PRD-A plants. Interestingly, a similar transient increase of leaf ethylene evolution after re-watering cotton plants (Morgan et al., 1990) was not attributed to root-to-shoot ACC signalling, even though ACC had previously been identified in xylem sap (Bradford and Yang, 1980). Thus, a model of root-to-shoot signalling of PRD plants that adequately predicted changes in xylem ABA concentration (Dodd et al., 2008a; b) seemed to account for changes in xylem ACC concentration before, but not after, re-watering.

Whether these changes in root-to-shoot ACC signalling (Fig. 5C) following PRD alternation best explain enhanced leaf ethylene evolution (Fig. 5E) was also investigated by comparing the magnitude of different ethylene-related responses. Compared to DI plants that were also re-watered, PRD-A plants showed increases in leaf xylem ACC concentration (4.3-fold), leaf ACC concentration (4.1-fold), ACO activity (1.4-fold) and ethylene evolution (1.8-fold), consistent with indications that root export of ACC can 
account for leaf ethylene evolution (Else and Jackson, 1998). Similarly, leaf xylem ACC concentration was linearly related to foliar ethylene evolution in different grant combinations of tomato (Dodd et al., 2009). However, only part of the additional ACC in PRD-A plants is converted to ethylene, with the remainder conjugated (malonylated Finlayson et al., 1991) or deaminated (McDonnell et al., 2009). While drought (Zhang et al., 2018) and flooding (English et al., 1995) can double leaf ACC oxidase activity, and modulate petiole epinasty in response to flooding, the more modest changes in ACO activity detected here suggests it is unlikely to account for increased leaf ethylene evolution following re-watering. Since these measurements occurred only 2 hours after re-watering, they provide a snapshot of how ethylene biosynthesis may be regulated. Supplying ACC to the roots of hydroponically-grown plants only transiently enhanced leaf ethylene evolution, which returned to normal after 6 hours despite continued ACC uptake, with alternative processes minimising ACC accumulation and ethylene evolution (Finlayson et al., 1991). Thus, transient changes in foliar ethylene evolution in response to long-distance ACC signalling (Fig. 5C-F) may ultimately be regulated by local changes in the activities of enzymes other than ACO oxidase.

The physiological importance of ethylene evolution in stomatal regulation also needs to be considered. Stomatal conductance was better correlated with leaf xylem ABA concentration (Fig. 8C) than leaf xylem ACC concentration (Fig. 8D) and was not statistically correlated with leaf ethylene evolution (Fig. 8F). Conversely, leaf ethylene evolution may be controlled by $g_{s}$ by regulating ethylene release from internal leaf tissues, since normalising leaf ethylene by $g_{s}$ amplifies treatment differences (cf. Figs $5 \mathrm{E}, 6$ ), and makes the ethylene response of WW plants (with maximum stomatal conductance) more coherent with the ACC data. High leaf ethylene evolution should result from high leaf ACC concentrations and/or high leaf ACO activity, yet these had low values in WW plants (Fig. 5D, F), possibly because the ACC was converted to ethylene. Further evaluation of the utility of this normalised variable (Fig. 6) should utilise continuous monitoring of both stomatal conductance and ethylene evolution in leaf or whole plant cuvettes (Jauregui et al., 2018).

Tissue hormone ratios may better explain stomatal (Wilkinson et al., 2012) and vegetative growth (Valluru et al., 2016) responses than individual hormone concentrations, and different $\mathrm{ABA} / \mathrm{ethylene}$ ratios correlated $\left(\mathrm{R}^{2}=0.24-0.35\right)$ with stomatal conductance (Supplementary Table 2). Nevertheless, xylem ABA concentration best explained variation in tomato stomatal conductance (Fig. 8C) 
consistent with other studies (eg. Kudoyarova et al., 2007, Thompson et al., 2007), with different irrigation treatments causing variation in xylem but not leaf ABA concentrations (cf. Fig. 5A, B). Similarly, soil drying increased xylem ABA concentration but not leaf ABA concentration in maize coincident with stomatal closure and before any decrease in leaf water potential (Zhang and Davies, 1989). Since the treatments did not differ in leaf water potential (Table 2) and it was not correlated with stomatal closure (Fig. 8B), it is likely that chemical, and not hydraulic, signals predominantly regulated stomatal conductance. While this appeared to be ABAmediated, increased ethylene evolution following re-watering is likely involved in regulating growth.

Determining the source of additional ABA in PRD plants has attracted attention (Dodd et al., 2008 a, b; Puertolas et al., 2015), since root ABA accumulation in response to drying soil (Fig. 2A) may not enhance root-to-shoot ABA signalling as sap flow rate (and thus ABA delivery to the shoot) decreases as the soil dries (Dodd et al., 2008a). Indeed, a model that included the water-uptake fractions from each part of the root system better explained leaf xylem ABA concentration than average soil water content (Pérez-Pérez and Dodd, 2015). Interestingly, ABA concentration of the re-watered roots (Side B) remained high (Fig. 4A), with relative changes in ABA biosynthesis (NCED gene expression - Thompson et al., 2000), catabolism (8'-hydroxylase gene expression - Krochko et al., 1998) and import from the shoot (McAdam et al., 2016; Castro et al., 2019) all contributing to momentary ABA status. This relatively insensitive (ABA) response to alternating the wet and dry parts of the root system (Fig. 4A) contrasted with a more dynamic (ACC) response (Fig. 4B). Thus, re-watered roots (Side B) retained high ABA concentrations whereas ACC concentrations declined to wellwatered values. Likewise, roots only recently exposed to drying soil (Side A) had not yet accumulated ABA but had already increased ACC concentrations (cf. Fig. 4A, B). Taken together, these observations suggest hysteresis in the relationships between root hormone concentrations and momentary soil water status according to whether the soil is drying or has been re-watered. Whether adjusting the frequency of PRD alternation to maintain elevated root hormone concentrations is advantageous in stimulating root growth of PRD plants (Mingo et al., 2004) is uncertain.

To conclude, plant hormone status (especially xylem and leaf ACC concentration - Fig. 5C, D and normalised leaf ethylene evolution - Fig. 6) was most responsive to alternating irrigation between the wet and dry sides of PRD plants. While 
many studies impose a single drying cycle (e.g. Thompson et al., 2007; Castro et al., 2019), it seems important to investigate plant responses to soil drying and re-wetting cycles (Dodd et al., 2015), since these conditions may better represent commercial deficit irrigation practices (Pérez-Pérez et al., 2012) and rainfed environments with intermittent rainfall.

\section{ACKNOWLEDGMENTS}

We thank Mrs. María del Puerto Sánchez-Iglesias for technical assistance with the HPLC-MS-based plant hormone analysis. This research was funded by EU projects SIRRIMED [FP7-KBBE-2009-3-245159] and SHui [Project Number 773903] and Instituto Nacional de Investigación y Tecnología Agraria y Alimentaria (INIA), Subprograma Nacional de Recursos y Tecnologías Agrarias through the Project RTA2012-00102-00-00. Juan G. Pérez-Pérez gratefully acknowledges the postdoctoral contracts in the INIA-CCAA program, supplied by the INIA co-financed with the European Social Fund, and 'Ramón y Cajal' program [RYC-2015-17726], supplied by the Spanish Ministry of Economy, Industry and Competitiveness (MINECO) and the 'Fundación Séneca' [18689/EE/12] and [19629/EE/14] for the fellowships to support his research at Lancaster.

\section{CRediT AUTHOR STATMENT}

Juan G. Pérez-Pérez: Conceptualization, Methodology, Investigation, Data-Curation, writing-original-draft.

Jaime Puertolas: Investigation, Writing - Review \& Editing.

Alfonso Albacete: Formal analysis, Resources.

Ian C. Dodd: Writing - Review \& Editing, Funding acquisition, Supervision.

\section{REFERENCES}

Acharya, B.R., \& Assmann, S.M. (2009) Hormone interactions in stomatal function. Plant Molecular Biology, 69(4), 451-462.

Albacete, A., Ghamen, M.E., Martínez-Andújar, C., Acosta, M., Sánchez-Bravo, J., Martínez, V., Lutts, S., Dodd, I.C., \& Pérez-Alfocea, F. (2008) Hormonal changes in relation to biomass partitioning and shoot growth impairment in salinized tomato (Solanum lycopersicum L.) plants. Journal of Experimental Botany, 59(15), 41194131. 
Andersen, L., Williams, S.H., \& Serek, M. (2004) Reduced water availability improves drought tolerance of potted miniature roses: is the ethylene pathway involved. Journal of Horticultural Science \& Biotechnology 79, 1-13.

Arve, L.E., \& Torre, S. (2015) Ethylene is involved in high air humidity promoted stomatal opening of tomato (Lycopersicon esculentum) leaves. Functional Plant Biology, 42, 376-386.

Barnawal, D., Bharti, N., Pandey, S.S., Pandey, A., Chanotiya, C.S., \& Kalra, A. (2017) Plant growth-promoting rhizobacteria enhance wheat salt drought stress tolerance by altering endogenous phytohormone levels and TaCTR1/TaDREB2 expression. Physiologia Plantarum, 161, 502-514.

Beguerisse-Diaz, M., Hernández-Gómez, M.C., Lizzul, A.M., Barahona, M., \& Desikan, R. (2012). Compound stress response in stomatal closure: a mathematical model of ABA and ethylene interaction in guard cells. BMC Systems Biology, 6, 146.

Belimov, A., Dodd, I.C., Hontzeas, N., Theobald, J.C., Safronova, V.I., \& Davies, W.J. (2009) Rhizosphere bacteria containing 1-aminocyclopropane-1-carboxylate deaminase increase yield of plants grown in drying soil via both local and systemic hormone signalling. New Phytologist, 181, 413-423.

Beltrano, J., Ronco, M.G., \& Montaldi, E.R. (1999). Drought stress syndrome in wheat is provoked by ethylene evolution imbalance and reversed by rewatering, aminoethoxyvinylglycine, or sodium benzoate. Journal of Plant Growth Regulation, $18,59-64$.

Bradford, K.J., \& Hsiao, T.C. (1982) Stomatal behaviour and water relations of water logged tomato plants. Plant Physiology, 70, 1508-1513.

Bradford, K.J., \& Yang, S.F. (1980) Xylem transport of 1-aminocyclopropane-1carboxylic acid, an ethylene precursor, in waterlogged tomato plants. Plant Physiology, 65, 322-326.

Bulens, I., Van de Poel, B., Hertog, M. L., De Proft, M. P., Geeraerd, A. H., \& Nicolaï, B. M. (2011). Protocol: An updated integrated methodology for analysis of metabolites and enzyme activities of ethylene biosynthesis. Plant Methods, 7(1), 17. https://doi.org/10.1186/1746-4811-7-17

Castro, P., Puertolas, J., \& Dodd, I.C. (2019) Stem girdling uncouples soybean stomatal conductance from leaf water potential by enhancing leaf xylem ABA concentration. Environmental and Experimental Botany, 159, 149-156.

Chen, L., Dodd, I.C., Davies, W.J., \& Wilkinson, S. (2013) Ethylene limits abscisic acid- or soil drying-induced stomatal closure in aged wheat leaves. Plant, Cell \& Environment, 36, 1850-1859.

Dodd, I.C. (2005) Root-to-shoot signalling: assessing the roles of 'up' in the up and down world of long-distance signalling in planta. Plant and Soil, 274, 251-270. doi:10.1007/s11104-004-0966-0

Dodd, I.C. (2009) Rhizosphere manipulations to maximise 'crop per drop' during deficit irrigation. Journal of Experimental Botany, 60, 2454-2459.

Dodd, I.C., Egea, G., \& Davies, W.J. (2008a). Abscisic acid signalling when soil moisture is heterogeneous: decreased photoperiod sap flow from drying roots limits abscisic acid export to the shoots. Plant, Cell \& Environment, 31, 1263-1274.

Dodd, I.C., Egea, G., \& Davies, W.J. (2008b). Accounting for sap flow from different parts of the root system improves the prediction of xylem ABA concentration in plants grown with heterogeneous soil moisture. Journal of Experimental Botany, 59, 4083-4093.

Dodd, I.C., Puértolas, J., Huber, K., Pérez-Pérez, J.G., Wright, H.R., \& Blackwell, M.S.A. (2015). The importance of soil drying and re-watering in crop phytohormonal 
and nutritional responses to deficit irrigation. Journal of Experimental Botany, 66, 2239-2252.

Dodd, I.C., Theobald, J.C., Bacon, M.A., \& Davies, W.J. (2006). Alternation of wet and dry sides during partial rootzone drying irrigation alters root-to-shoot signalling of abscisic acid. Functional Plant Biology, 33, 1081-1089. https://doi.org/10.1071/FP06203.

Dodd, I.C., Theobald, J.C., Richer, S.K., \& Davies, W.J. (2009) Partial phenotypic reversion of ABA-deficient flacca tomato (Solanum lycopersicum) scions by a wildtype rootstock: normalising shoot ethylene relations promotes leaf area but does not diminish whole plant transpiration rate. Journal of Experimental Botany, 60, 40294039.

Dry, P.R., Loveys, B.R., Botting, D., \& During, H. (1996) Effects of partial rootzone drying on grapevine vigour, yield, composition of fruit and use of water. In: 'Proceedings of the 9th Australian wine industry technical conference'. (Eds CS Stockley, AN Sas, RS Johnstone, TH Lee) pp. 126-131. (Winetitles: Adelaide).

Dry, P.R., Loveys, B.R., \& Düring, H. (2000) Partial drying of the rootzone of grape. I. Transient changes in shoot growth and gas exchange. Vitis, 39, 3-7.

Else, M.A., \& Jackson, M.B. (1998) Transport of 1-aminocyclopropane-1-carboxylic acid (ACC) in the transpiration stream of tomato (Lycopersicon esculentum) in relation to foliar ethylene production and petiole epinasty. Australian Journal of Plant Physiology, 25, 453-458.

Else, M.A., Hall, K.C., Arnold, G.M., Davies, W.J., \& Jackson, M.B. (1995) Export of abscisic acid, 1 aminocyclopropane-1-carboxylic acid, phosphate, and nitrate from roots to shoots of flooded tomato plants - accounting for the effects of xylem sap flow rate on concentration and delivery. Plant Physiology, 107, 377-384.

English, P.J., Lycett, G.W., Roberts, J.A., \& Jackson, M.B. (1995) Increased 1aminocyclopropane-1-carboxylic acid oxidase activity in shoots of flooded tomato plants raises ethylene production to physiologically active levels. Plant Physiology, 109, 1435-1440.

Fereres, E. \& Soriano, M.A. (2007) Deficit irrigation for reducing agricultural water Use. Journal of Experimental Botany, 58, 147-159.

Fiebig, A., \& Dodd, I.C. (2016) Inhibition of tomato shoot growth by over-irrigation is linked to nitrogen deficiency and ethylene. Physiologia Plantorum, 156, 70-83.

Finlayson, S.A., Foster, K.R., \& Reid, D. M. (1991) Transport and metabolism of 1aminocyclopropane- 1-carboxylic acid in sunflower (Helianthus annuus L.) seedlings. Plant Physiology, 96, 1360-1367. doi: 10.1104/pp.96.4.1360

Haghighi, M., France, J., Behboudian, M.H., \& Mills, T.M. (2013) Fruit quality responses of 'Petopride' processing tomato (Lycopersicon esculentum Mill.) to partial rootzone drying. Journal of Horticultural Science \& Biotechnology, 88(2), 154-159.

Ibort, P., Molina, S., Ruiz-Lozano, J.M., \& Aroca, R. (2018) Molecular insights into the involvement of a never ripe receptor in the interaction between two beneficial soil bacteria and tomato plants under well-watered and drought conditions. Molecular Plant-Microbe Interactions, 31(6), 633-650.

Jauregui, I., Rothwell, S.A., Taylor, S.H., Parry, M.A.J., Carmo-Silva, E., \& Dodd, I.C. (2018) Whole plant chamber to examine sensitivity of cereal gas exchange to changes in evaporative demand. Plant Methods, 14, 97. doi:10.1186/s13007-018$0357-9$ 
Kang, S., \& Zhang, J. (2004). Controlled alternate partial root-zone irrigation: Its physiological consequences and impact on water use efficiency. Journal of Experimental Botany, 55(407), 2437-2446. https://doi.org/10.1093/jxb/erh249

Khalil, A.A.M., \& Grace, J. (1993) Does xylem sap ABA control the stomatal behaviour of water-stressed sycamore (Acer pseudoplatanus L.) seedlings? Journal of Experimental Botany, 44(7), 1127-1134.

Krochko, J.E., Abrams, G.D., Loewen, M.K., Abrams, S.R., \& Cutler, A.J. (1998) (+)Abscisic acid 8'-hydroxylase is a cytochrome P450 monooxygenase. Plant Physiology, 118, 849-860.

Kudoyarova, G.R., Vysotskaya, L.B., Cherkozyanova, A., \& Dodd, I.C. (2007) Effect of partial rootzone drying on the concentration of zeatin-type cytokinins in tomato (Solanum lycopersicum L.) xylem sap and leaves. Journal of Experimental Botany, 58, 161-168.

Li, X., Wilkinson, S., Shen, J.B., Forde, B.G., \& Davies, W.J. (2017) Stomatal and growth responses to hydraulic and chemical changes induced by progressive soil drying Journal of Experimental Botany, 68, 5883-5894.

Lizada, M.C.C., \& Yang, S.F. (1979) Simple and sensitive assay for 1aminocyclopropane-1-carboxylic acid. Analytical Biochemistry, 100, 140-145.

Madhavan, S., Chrmoinski, A., \& Smith, B.N. (1983) Effect of ethylene on stomatal opening in tomato and carnation leaves. Plant and Cell Physiology, 24, 569-572.

Martínez-Andújar, C., Albacete, A., Martínez-Pérez, A., Pérez-Pérez, J.M., Asins, M.J. \& Pérez-Alfocea, F. (2016) Root-to-shoot hormonal communication in contrasting rootstocks suggests an important role for the ethylene precursor aminocyclopropane1-carboxylic acid in mediating plant growth under low-potassium nutrition in tomato. Frontiers in Plant Science, 7, 1782.

Mayak, S., Tirosh, T., \& Glick, B.R. (2004) Plant growth-promoting bacteria that confer resistance to water stress in tomatoes and peppers. Plant Science, 166, 525-530.

McAdam, S.A.M., Brodribb, T.J., Ross, J.J. (2016). Shoot derived abscisic acid promotes root growth. Plant Cell \& Environment. 39, 652-659.

McDonnell, L., Plett, J.M., Andersson-Gunneras, S., Kozela, C., Dugardeyn, J., Van Der Straeten, D., Glick, B.R., Sundberg, B., Regan, S. (2009) Ethylene levels are regulated by a plant encoded 1-aminocyclopropane-1-carboxylic acid deaminase. Physiologia Plantorum, 136, 94-109. doi: 10.1111/j.1399-3054.2009.01208.x

Mingo, D. M., Theobald, J. C., Bacon, M. A., Davies, W. J., \& Dodd, I. C. (2004). Biomass allocation in tomato (Lycopersicon esculentum) plants grown under partial rootzone drying: enhancement of root growth. Functional Plant Biology, 31, 971978.

Morgan, P.W., He, C.J., De Greef, J.A., \& De Proft, M.P. (1990) Does water deficit stress promote ethylene synthesis by intact plants? Plant Physiology, 94, 1616-1624.

Nazareno, A.L., \& Hernández, B.S. (2017) A mathematical model of the interaction of abscisic acid, ethylene and methyl jasmonate on stomatal closure in plants. PLoS ONE, 12(2), e0171065.

Pérez-Pérez, J. G., Dodd, I. C., \& Botía, P. (2012). Partial rootzone drying increases water-use efficiency of lemon Fino 49 trees independently of root-to-shoot ABA signalling. Functional Plant Biology, 39, 366-378. https://doi.org/10.1071/FP11269

Pérez-Pérez, J. G., Navarro, J. M., Robles, J. M., \& Dodd, I. C. (2018). Prolonged drying cycles stimulate ABA accumulation in Citrus macrophylla seedlings exposed to partial rootzone drying. Agricultural Water Management, 210, 271-278. https://doi.org/10.1016/j.agwat.2018.08.020 
Pérez-Pérez, J.G., \& Dodd, I.C. (2015). Sap fluxes from different parts of the rootzone modulate xylem ABA concentration during partial rootzone drying and re-wetting. Journal of Experimental Botany, 66, 2315-2324.

Pierik, R., Tholen, D., Poorter, H., Visser, E.J.W., \& Voesenek, L.A.C.J. (2006) The Janus face of ethylene: growth inhibition and stimulation. Trends in Plant Science, 11(4), 176-183.

Puertolas, J., Conesa, M. R., Ballester, C., \& Dodd, I. C. (2015) Local root abscisic acid (ABA) accumulation depends on the spatial distribution of soil moisture in potato: Implications for ABA signalling under heterogeneous soil drying. Journal of Experimental Botany, 66(8), 2325-2334. https://doi.org/10.1093/jxb/eru501

Quarrie, S.A., Whitford, P.N., Appleford, N.E.J., Wang, T.L., Cook, S.K., Henson, I.E., \& Loveys, B.R. (1988). A monoclonal-antibody to (S)-abscisic acid: its characterization and use in a radioimmunoassay for measuring abscisic- acid in crude extracts of cereal and lupin leaves. Planta, 173, 330-339.

Rodriguez-Dominguez, C.M., Buckley, T.N., Egea, G., de Cires, A., HernándezSantana, V., Martorell, S., \& Diaz-Espejo, A. (2016) Most stomatal closure in woody species under moderate drought can be explained by stomatal responses to leaf turgor. Plant, Cell \& Environment, 39, 2014-2026.

Romero, P., Dodd, I.C., Martinez-Cutillas, A. (2012) Contrasting physiological effects of partial root-zone drying in field-grown grapevine (Vitis vinifera L. cv. Monastrell) according to total soil water availability. Journal of Experimental Botany, 63, 40714083.

Sobeih, W. Y., Dodd, I. C., Bacon, M. A., Grierson, D., \& Davies, W. J. (2004). Longdistance signals regulating stomatal conductance and leaf growth in tomato (Lycopersicon esculentum) plants subjected to partial root-zone drying. Journal of Experimental Botany, 55(407), 2353-2363. https://doi.org/10.1093/jxb/erh204

Stoll, M., Loveys, B., \& Dry, P. (2000). Hormonal changes induced by partial rootzone drying of irrigated grapevine. Journal of Experimental Botany, 51, 1627-1634.

Tanaka, Y., Sano, T., Tamaoki, M., Nakajima, N., Kondo, N., \& Hasezawa, S. (2005) Ethylene inhibits abscisic acid-induced stomatal closure in Arabidopsis. Plant Physiology, 138, 2337-2343.

Thompson, A.J., Jackson, A.C., Parker, R.A., Morpeth, D.R., Burbidge, A., \& Taylor, I.B. (2000) Abscisic acid biosynthesis in tomato: regulation of zeaxanthin epoxidase and 9-cis-epoxycarotenoid dioxygenase mRNAs by light/dark cycles, water stress and abscisic acid. Plant Molecular Biology, 42, 833-845.

Thompson, A.J., Mulholland, B.J., McKee, J.M.T., Hilton, H.W., Horridge, J.S., Farquar, G.D., Smeeton, R.C., Smillie, I.R.A., Black, C.R., \& Taylor, I.B. (2007) Overproduction of abscisic acid in tomato increases transpiration efficiency and root hydraulic conductivity and influences leaf expansion. Plant Physiology, 143, 19051917.

Tudela, D., \& Primo-Millo, E. (1992). 1-Aminocyclopropane-1-Carboxylic Acid Transported from Roots to Shoots Promotes Leaf Abscission in Cleopatra Mandarin (Citrus reshni Hort. ex Tan.) Seedlings Rehydrated after Water Stress. Plant Physiology, 100, 131-137. https://doi.org/10.1104/pp.100.1.131

Valluru, R., Davies, W.J., Reynolds, M.P., \& Dodd, I.C. (2016) Foliar abscisic acid-toethylene accumulation and response regulate shoot growth sensitivity to mild drought in wheat. Frontiers in Plant Science, 7, 461.

Wang, T., Liu, F., Andersen, M.N., \& Jensen, C.R. (2010) Improved plant nitrogen nutrition contributes to higher water use efficiency in tomatoes under alternate partial root-zone irrigation. Functional Plant Biology, 37, 175-182. 
Wilkinson, S., Kudoyarova, G.R., Veselov, D.S., Arkhipova, T.N., \& Davies, W.J. (2012) Plant hormone interactions: innovative targets for crop breeding and management. Journal of Experimental Botany, 63, 3499-3509.

Zhang, G., Sun, Y., Sheng, H., Li, H., \& Liu, X. (2018) Effects of the inoculations using bacteria producing ACC deaminase on ethylene metabolism and growth of wheat grown under different soil water contents. Plant Physiology and Biochemistry, 125, 178-184.

Zhang, J., \& Davies, W.J. (1989) Abscisic acid produced in dehydrating roots may be enable the plant to measure the water status of the soil. Plant, Cell \& Environment, 12(1), 73-81. 
Table 1. Average whole pot soil water content $\left(\theta_{\mathrm{pot}}\right)$, leaf water potential ( $\left.\Psi_{\text {leaf }}\right)$, plant water uptake, leaf photosynthesis $(A)$, stomatal conductance $\left(g_{s}\right)$ and intrinsic water use efficiency $\left(A / g_{s}\right)$ of WW, DI and PRD-F plants - (Experiment 1$)$. Physiological measurements were made in Leaf 7 (numbering from the base of the plant).

\begin{tabular}{ccccccc}
\hline Irrigation treatment & $\begin{array}{c}\theta_{\text {pot }} \\
\left(\mathrm{g} \mathrm{g}^{-1}\right)\end{array}$ & $\begin{array}{c}\Psi_{\text {leaf }} \\
(\mathrm{MPa})\end{array}$ & $\begin{array}{c}\text { Water uptake } \\
\left(\mathrm{mg} \mathrm{H}_{2} \mathrm{O} \mathrm{s}^{-1}\right)\end{array}$ & $\begin{array}{c}A \\
\left(\mu \mathrm{mol} \mathrm{CO} 2 \mathrm{~m}^{-2} \mathrm{~s}^{-1}\right)\end{array}$ & $\begin{array}{c}g_{s} \\
\left(\mathrm{~mol} \mathrm{H}_{2} \mathrm{O} \mathrm{m}^{-2} \mathrm{~s}^{-1}\right)\end{array}$ & $\begin{array}{c}A / g_{s} \\
\left(\mu \mathrm{mol} \mathrm{CO}_{2} \mathrm{~mol}^{-1} \mathrm{H}_{2} \mathrm{O}\right)\end{array}$ \\
\hline WW & $0.38 \pm 0.01 \mathrm{a}$ & $-0.71 \pm 0.04$ & $17.0 \pm 1.5 \mathrm{a}$ & $11.1 \pm 0.7$ & $0.41 \pm 0.07$ & $28 \pm 3.0$ \\
DI & $0.28 \pm 0.01 \mathrm{~b}$ & $-0.75 \pm 0.01$ & $14.3 \pm 1.1 \mathrm{a}$ & $10.4 \pm 0.4$ & $0.35 \pm 0.04$ & $34 \pm 4.0$ \\
PRD-F & $0.28 \pm 0.01 \mathrm{~b}$ & $-0.71 \pm 0.03$ & $10.7 \pm 0.8 \mathrm{~b}$ & $9.3 \pm 0.7$ & $0.29 \pm 0.04$ & $39 \pm 4.7$ \\
\hline$P$-value & $<0.0001$ & 0.401 & 0.006 & 0.269 & 0.376 & 0.471 \\
\hline
\end{tabular}

Within each column, different letters indicate significant differences between means at $P \leq 0.05$ by Tukey's test, with $P$ values for 1 -way ANOVA. Data are means \pm standard error $(n=4, n=11$ and $n=13$ for WW, DI and PRD-F respectively). 
Table 2. Average whole pot soil water content $\left(\theta_{\text {pot }}\right)$, leaf water potential $\left(\Psi_{\text {leaf }}\right)$, plant water uptake, leaf photosynthesis $(A)$, stomatal conductance $\left(g_{s}\right)$ and intrinsic water use efficiency $\left(A / g_{s}\right)$ of WW, DI, PRD-F, DI-RW and PRD-A plants - (Experiment 2). Measurements were made at the end of a drying cycle (DI and PRD-F plants) when soil moisture was comparable in both treatments, and 2 hours after re-watering DI and PRD-A plants. Physiological measurements were made in Leaf 7 (numbering from the base of the plant).

\begin{tabular}{|c|c|c|c|c|c|c|}
\hline Irrigation treatment & $\begin{array}{c}\theta_{\text {pot }} \\
\left(\mathrm{g} \mathrm{g}^{-1}\right)\end{array}$ & $\begin{array}{c}\Psi_{\text {leaf }} \\
(\mathrm{MPa})\end{array}$ & $\begin{array}{l}\text { Water uptake } \\
\left(\mathrm{mg} \mathrm{H}_{2} \mathrm{O} \mathrm{s}^{-1}\right)\end{array}$ & $\begin{array}{c}A \\
\left(\mu \mathrm{mol} \mathrm{CO} 2 \mathrm{~m}^{-2} \mathrm{~s}^{-1}\right)\end{array}$ & $\begin{array}{c}g_{s} \\
\left(\mathrm{~mol} \mathrm{H}_{2} \mathrm{O} \mathrm{m}^{-2} \mathrm{~s}^{-1}\right)\end{array}$ & $\begin{array}{c}A / g_{s} \\
\left(\mu \mathrm{mol} \mathrm{CO} 2 \mathrm{~mol}^{-1} \mathrm{H}_{2} \mathrm{O}\right)\end{array}$ \\
\hline DI & $0.26 \pm 0.01 \mathrm{c}$ & $-0.76 \pm 0.02$ & $14.4 \pm 1.7 \mathrm{bc}$ & $10.6 \pm 0.6$ & $0.37 \pm 0.07 \mathrm{ab}$ & $33 \pm 5.3 b$ \\
\hline PRD-F & $0.26 \pm 0.01 \mathrm{c}$ & $-0.70 \pm 0.04$ & $11.1 \pm 1.2 \mathrm{c}$ & $10.2 \pm 0.8$ & $0.33 \pm 0.06 \mathrm{ab}$ & $35 \pm 4.5 \mathrm{~b}$ \\
\hline PRD-A & $0.33 \pm 0.01 \mathrm{~b}$ & $-0.70 \pm 0.03$ & $14.8 \pm 1.5 \mathrm{bc}$ & $10.1 \pm 1.6$ & $0.22 \pm 0.05 \mathrm{~b}$ & $51 \pm 5.2 \mathrm{a}$ \\
\hline$P$-value & $<0.0001$ & 0.540 & 0.007 & 0.629 & 0.041 & 0.016 \\
\hline
\end{tabular}

Within each column, different letters indicate significant differences between means at $P \leq 0.05$ by Tukey's test, with $P$ values for 1 -way ANOVA. Data are means \pm standard error $(n=6)$. 
Table 3. The ability of different models to predict leaf xylem ACC concentration ([XACC] leaf) of PRD-F and PRD-A plants. [X-ACC] leaf was measured in detached leaves. For each plant, the difference between model (Equations 1 and 2) and measurements is calculated as the ratio $[\mathrm{X}-\mathrm{ACC}]_{\text {model }} /[\mathrm{X}-\mathrm{ACC}]_{\text {leaf. }}$ Values above or below 1 indicates that the model overestimates or underestimates $[\mathrm{X}-\mathrm{ACC}]$ leaf, respectively. The numbers in the brackets are the $n$ values.

\begin{tabular}{cccc}
\hline Irrigation treatment & Mean (Eq. 1) & Fractional (Eq. 2) & $\boldsymbol{P}$-value \\
\hline PRD-F & $1.28(6)$ & $0.93(6)$ & 0.322 \\
PRD-A & $0.56(6)$ & $0.57(6)$ & 0.969 \\
& & & \\
$\boldsymbol{P}$-value & 0.054 & 0.224 & \\
\hline
\end{tabular}



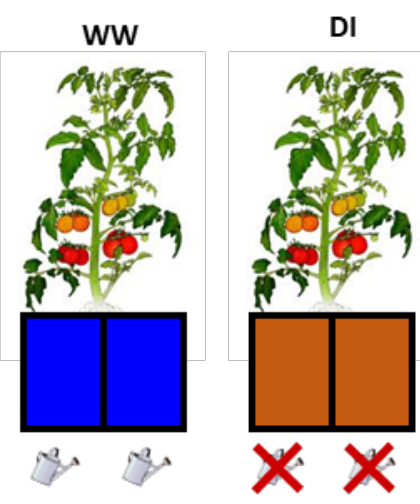

DI-RW

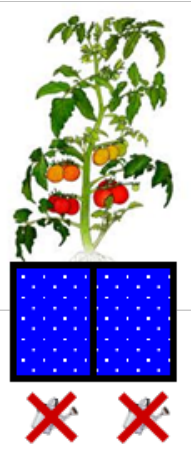



Side A Side B Side A Side B
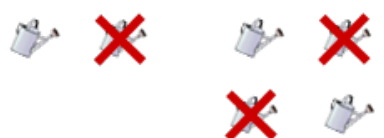

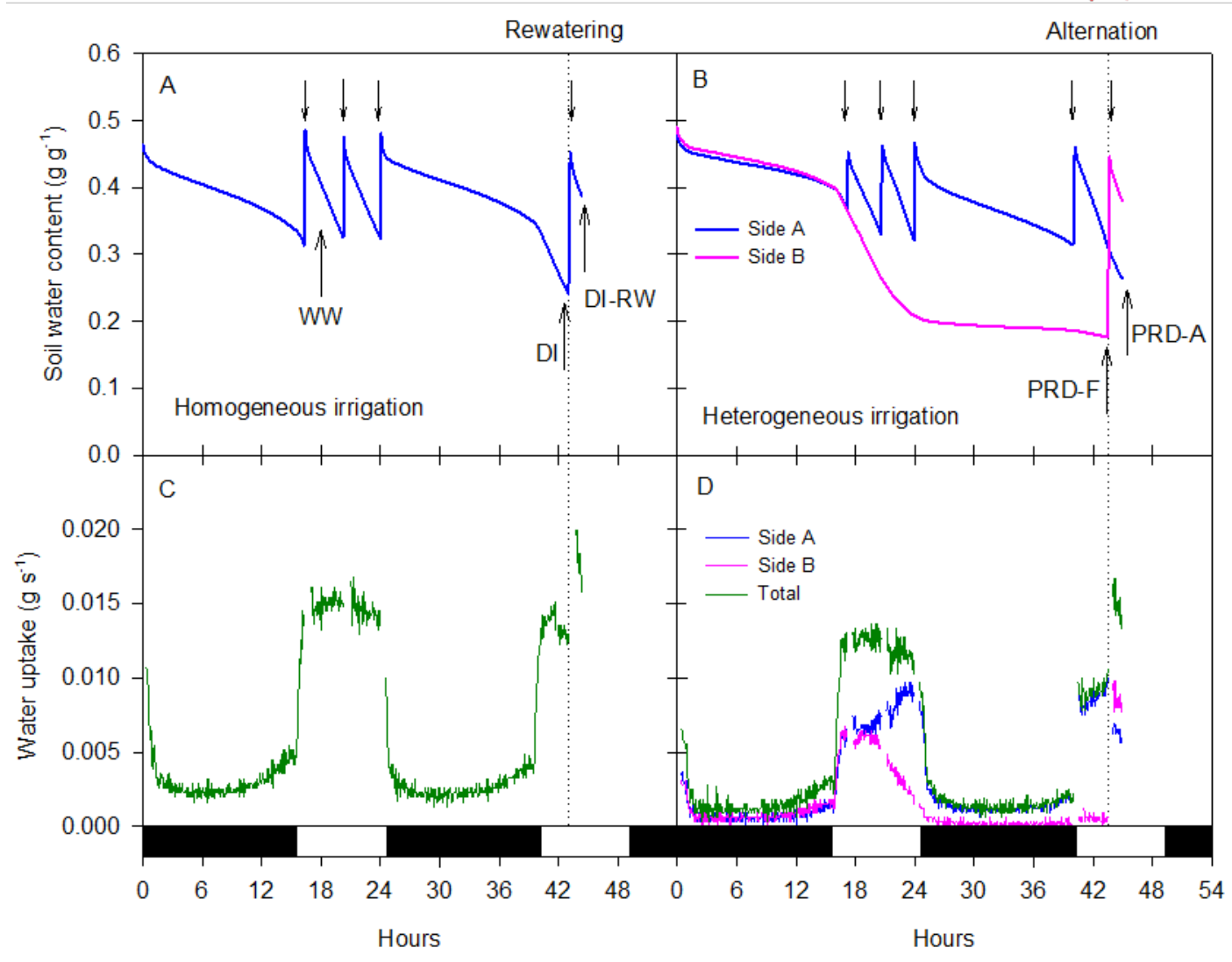

Figure 1. Soil water content (A and B) and water uptake (C and D) from plants irrigated homogeneously (WW, DI and DI-RW) and exposed to partial rootzone drying (PRD-F and PRD-A). Arrows indicate when plants of each irrigation treatment were sampled. Dotted vertical line indicates the re-watering (DI) or alternation (PRD) events. In DI treatments, soil water content corresponds to the average water uptake of the whole pot. In PRD treatments, soil water content and water uptake of each side of the pot are presented separately. Black bars on the $x$-axis indicate the night period. Images visually indicate the treatments based on soil water content values, with dotted colours indicating re-watering/alternation. Downward vertical arrows in panels A and B indicate the irrigation events. 


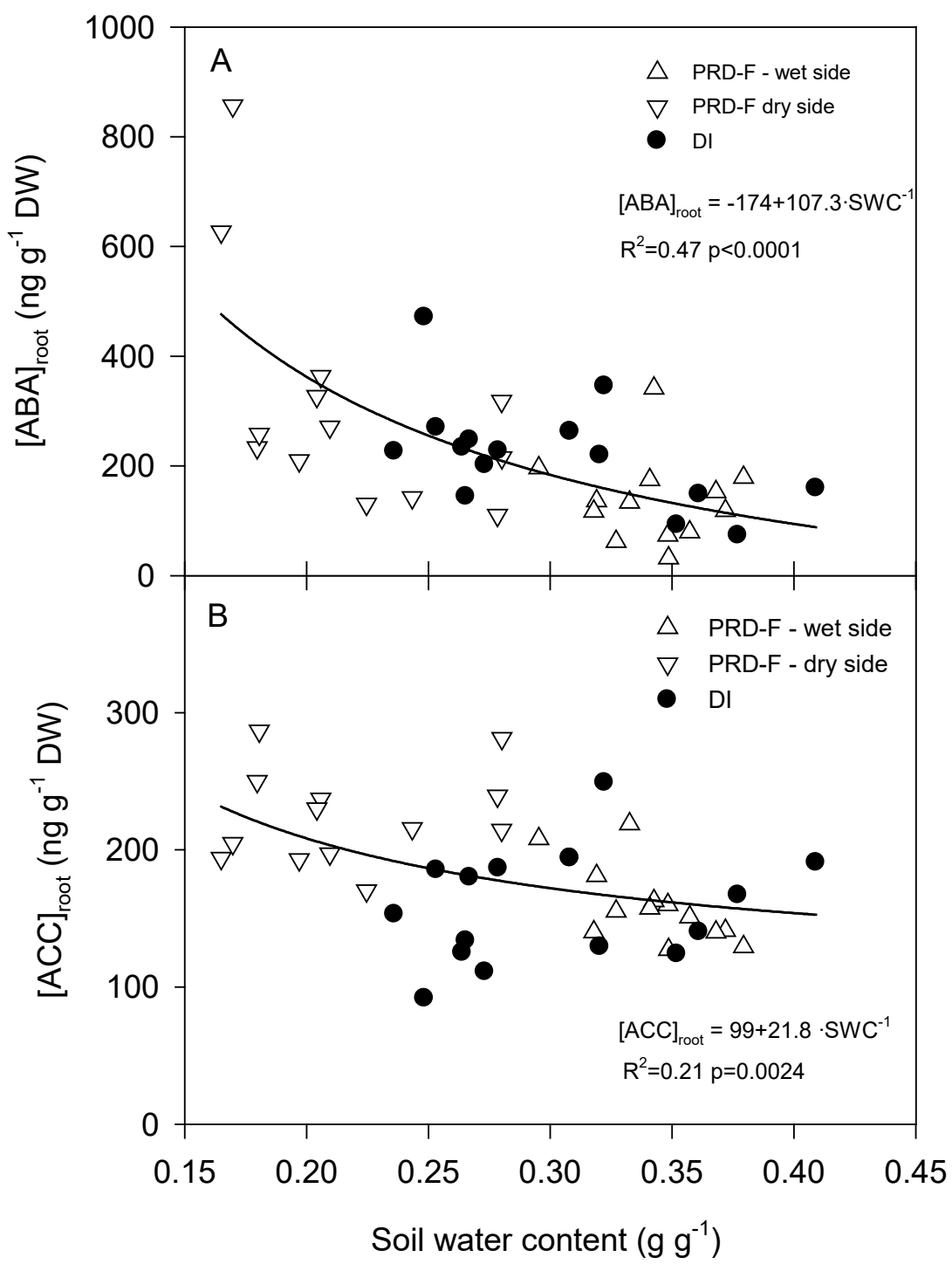

Figure 2. Relationship between root $\mathrm{ABA}$ concentration $[\mathrm{ABA}]_{\text {root }}(\mathrm{A})$ and root $\mathrm{ACC}$ concentration $[\mathrm{ACC}]_{\mathrm{root}}(\mathrm{B})$ and local soil water content for DI and PRD-F plants. Filled circles correspond to the average of the whole root system of DI plants and hollow triangles with each side of the root system of PRD-F plants. Each point represents a single measurement of an individual root system, with regression lines were fitted where significant $(P<0.05)$. 


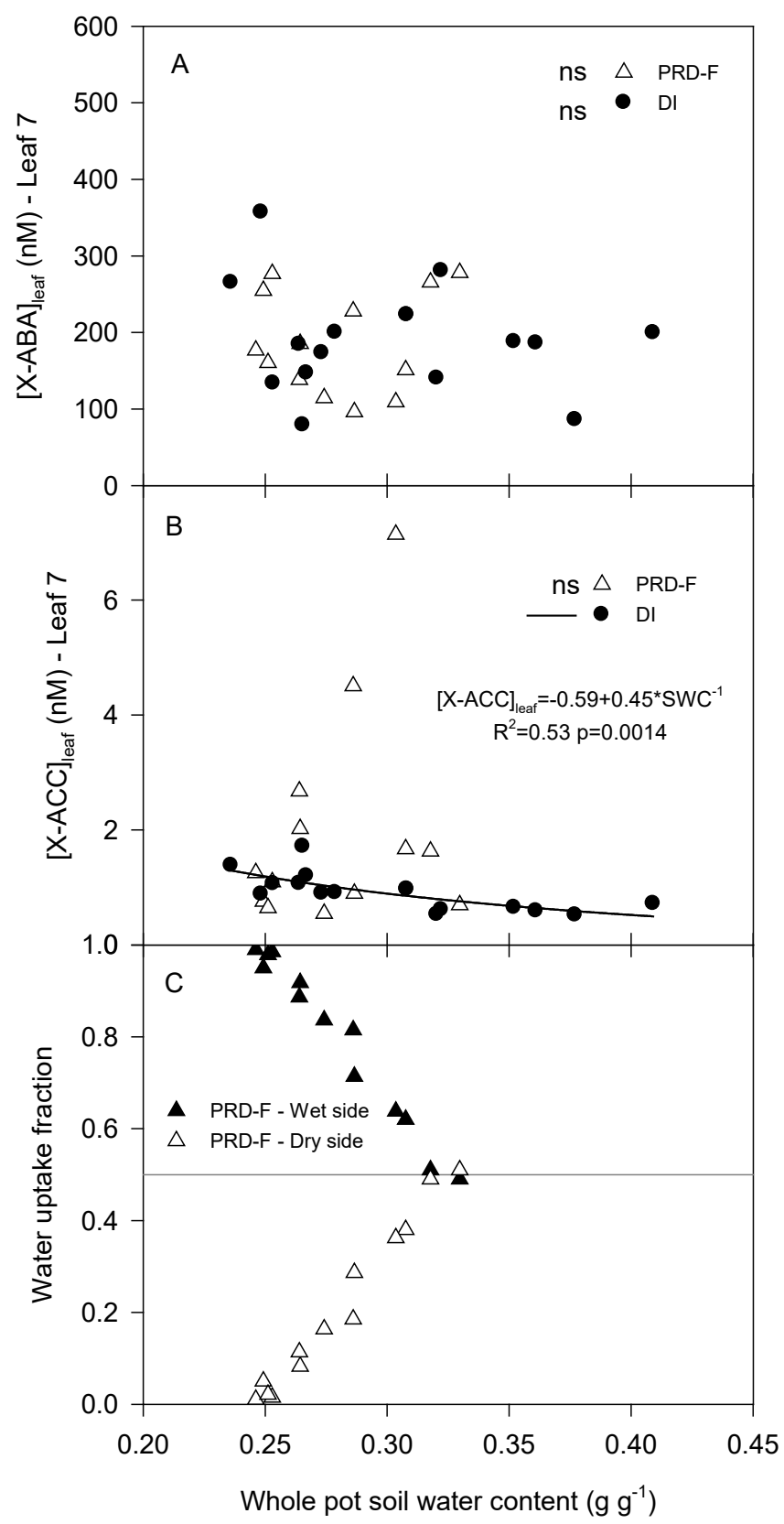

Figure 3. Relationships between leaf xylem ABA concentration ([X-ABA] leaf) $(\mathrm{A})$ and leaf xylem ACC concentration ([X-ACC $\left.]_{\text {leaf }}\right)(\mathrm{B})$ and whole pot soil water content for $\mathrm{DI}$ and PRD-F plants. Panel $\mathrm{C}$ shows the estimated water-uptake fraction for each side of the pot $v s$ whole pot soil water content for PRD-F plants. Filled circles correspond with the average of whole root system of DI plants and empty triangles with each side of the root system of PRD-F plants. Each point represents a single measurement of an individual plant and regression lines were fitted where significant $(P<0.05)$. 


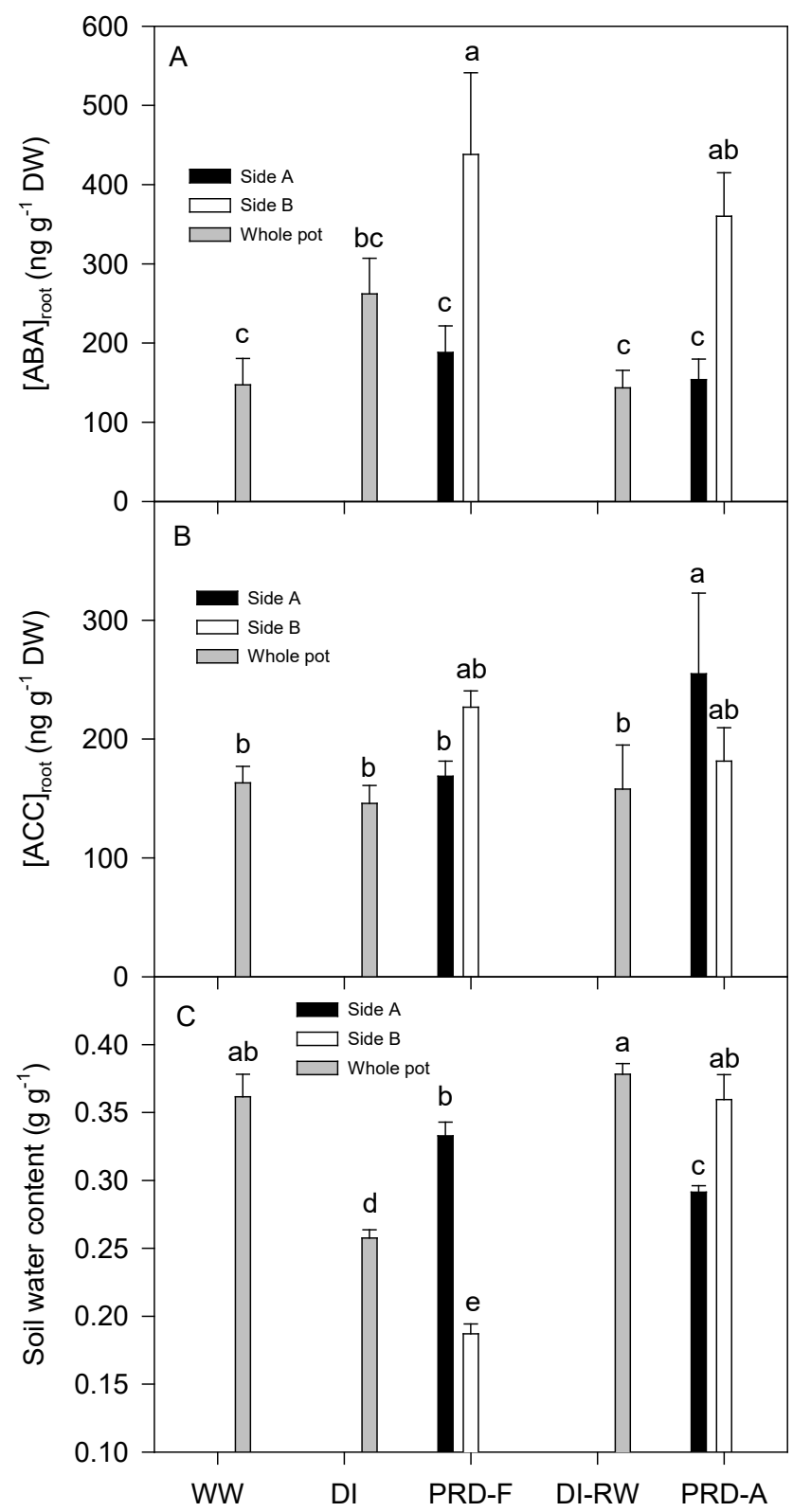

Figure 4. Root ABA concentration ([ABA $\left.]_{\text {root }}\right)(A)$, root ACC concentration ([ACC $\left.]_{\text {root }}\right)$ (B) and soil water content (C) of WW, DI, PRD-F, DI-RW and PRD-A plants. In the WW, DI and DI-RW treatments, the vertical bar indicates whole-pot values and in PRD-F and PRD-A treatments, each bar corresponds with each side of the pot. Vertical error bars indicate the standard error of the mean. Within each figure, different letters indicate significant differences between means at $P \leq 0.05$ by Tukey's test. 

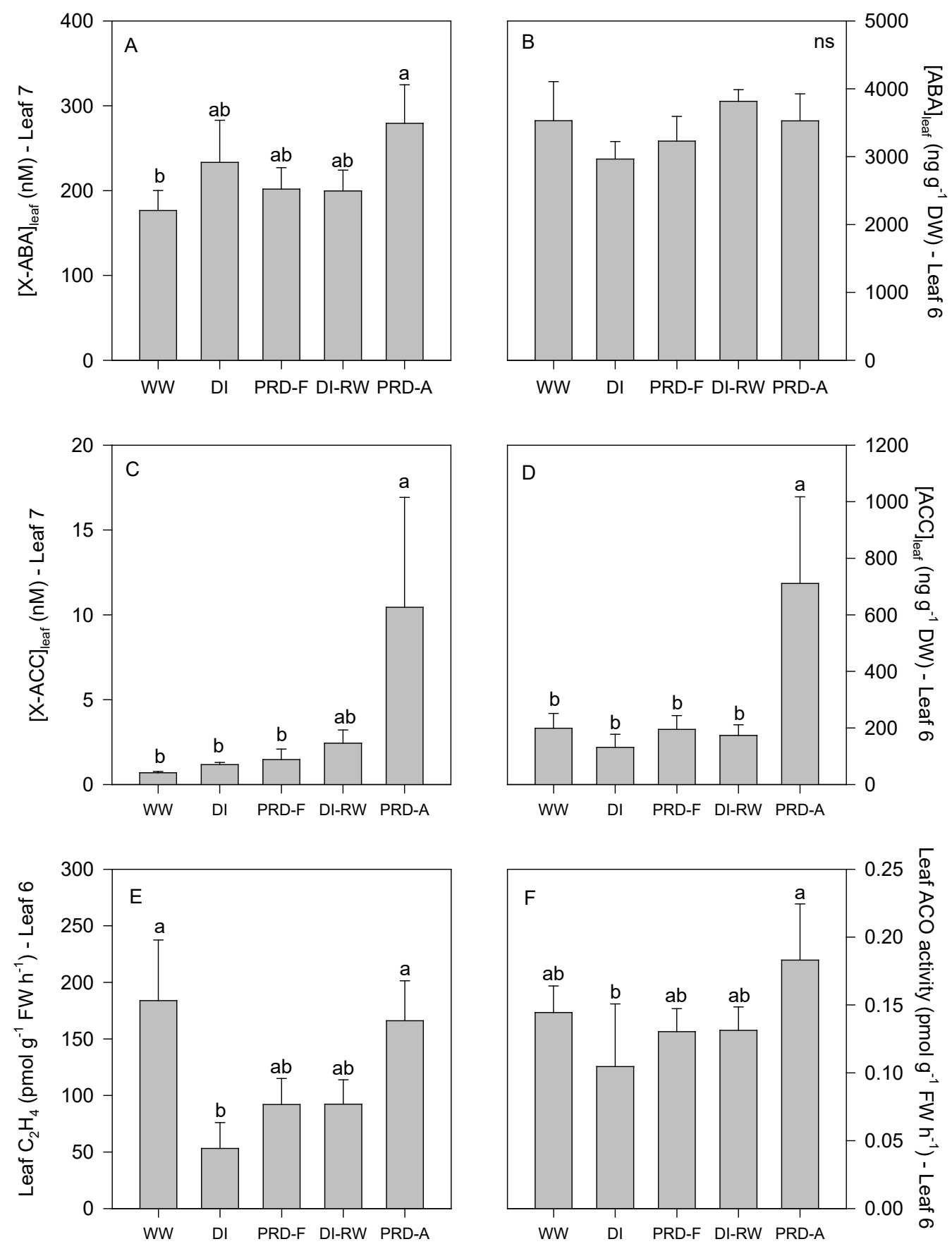

Figure 5. Leaf xylem ABA concentration ([X-ABA]leaf) (A), leaf ABA concentration ([ABA] leaf) (B), leaf xylem ACC concentration ([X-ACC] leaf) (C), leaf ACC concentration ([ACC] leaf) (D), leaf ethylene $\left(\mathrm{C}_{2} \mathrm{H}_{4}\right)$ evolution $(\mathrm{E})$, and leaf ACC oxidase activity (ACO) (F) of WW, DI, PRD-F, DI-RW and PRD-A plants. Within each figure, different letters indicate significant differences between means at $P \leq 0.05$ by Tukey's test. 


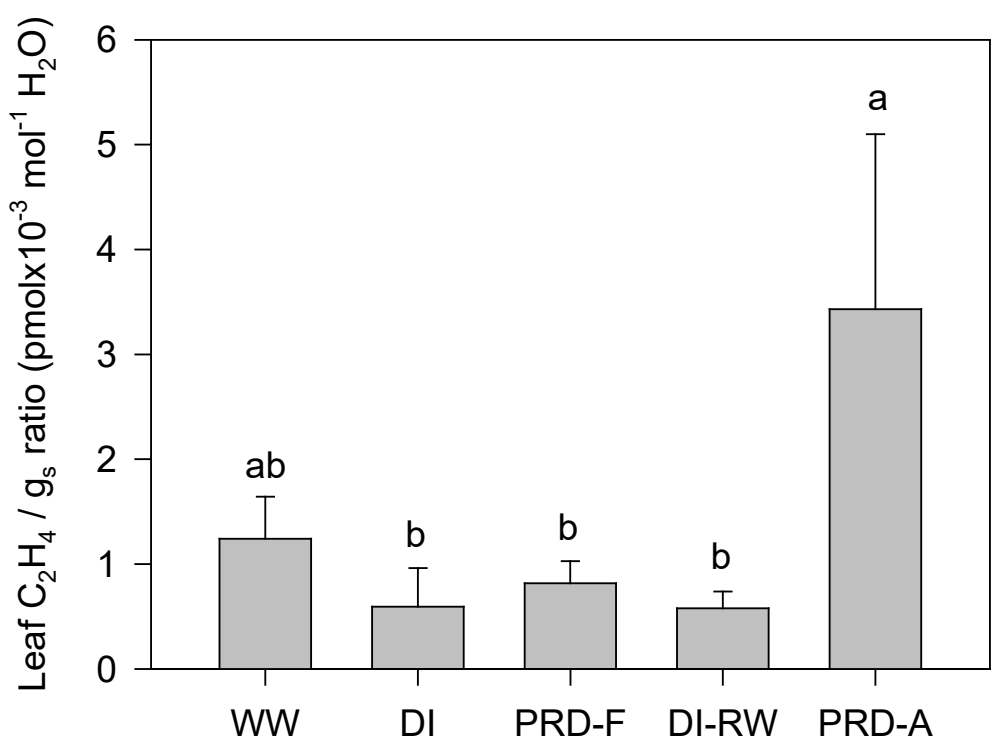

Figure 6. Leaf $\mathrm{C}_{2} \mathrm{H}_{4}$ (Leaf 6) and stomatal conductance $\left(g_{s}\right)$ (Leaf 7) ratio of WW, DI, PRD-F, DI-RW and PRD-A plants. Within each figure, different letters indicate significant differences between means at $P \leq 0.05$ by Tukey's test. 

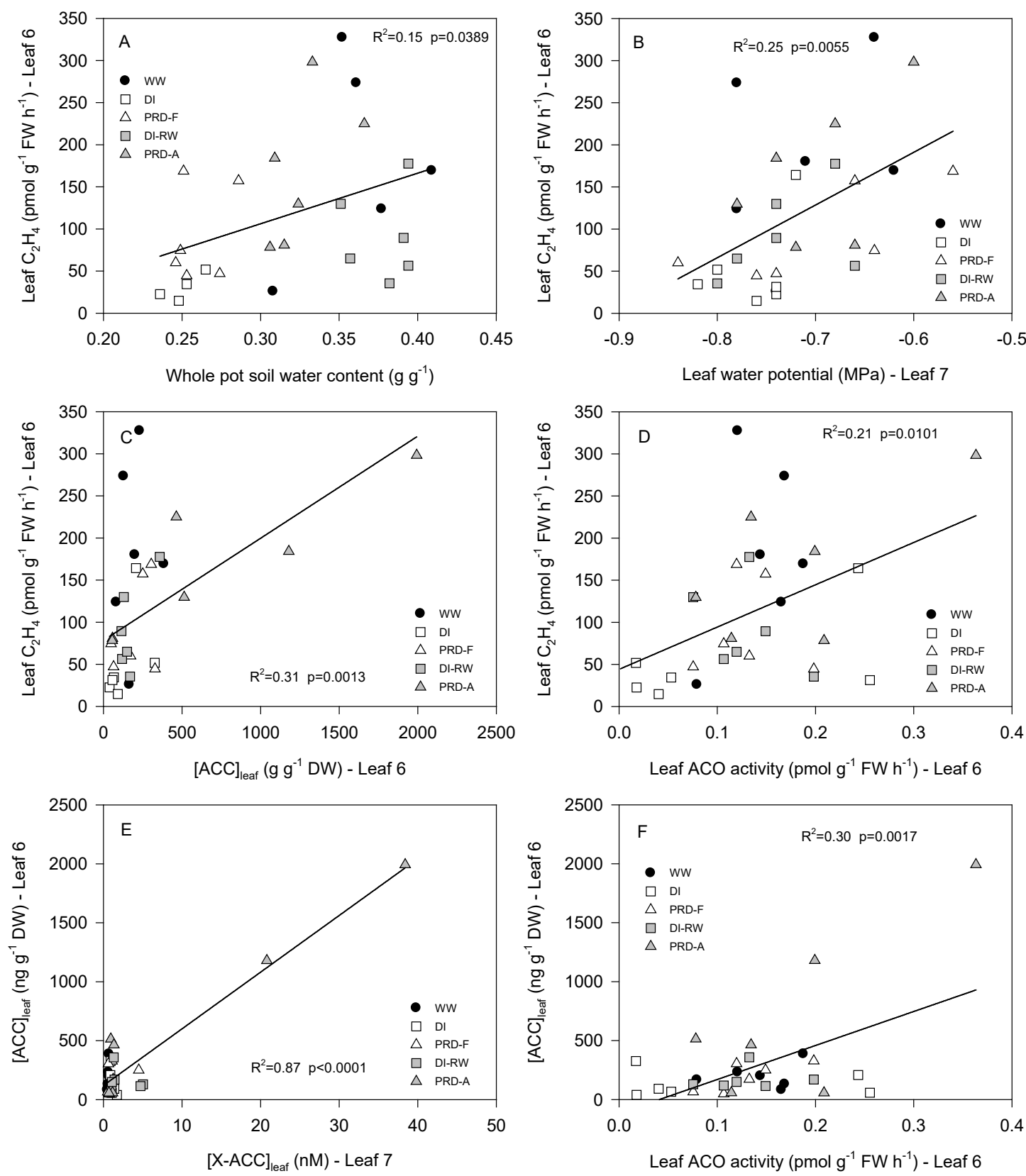

Figure 7. Relationships between leaf ethylene $\left(\mathrm{C}_{2} \mathrm{H}_{4}\right)$ evolution and whole pot soil water content (A), leaf water potential (B), leaf ACC concentration - $[\mathrm{ACC}]_{\text {leaf }}(\mathrm{C})$ and leaf ACC oxidase activity (ACO) activity (D), and between [ACC] leaf and leaf xylem ACC concentration - [X-ACC $]_{\text {leaf }}(\mathrm{E})$ and leaf ACO activity (F) for WW, DI, PRD-F, DI-RW and PRD-A plants. Each point represents a single measurement of an individual plant and regression lines were fitted where significant $(P<0.05)$. 

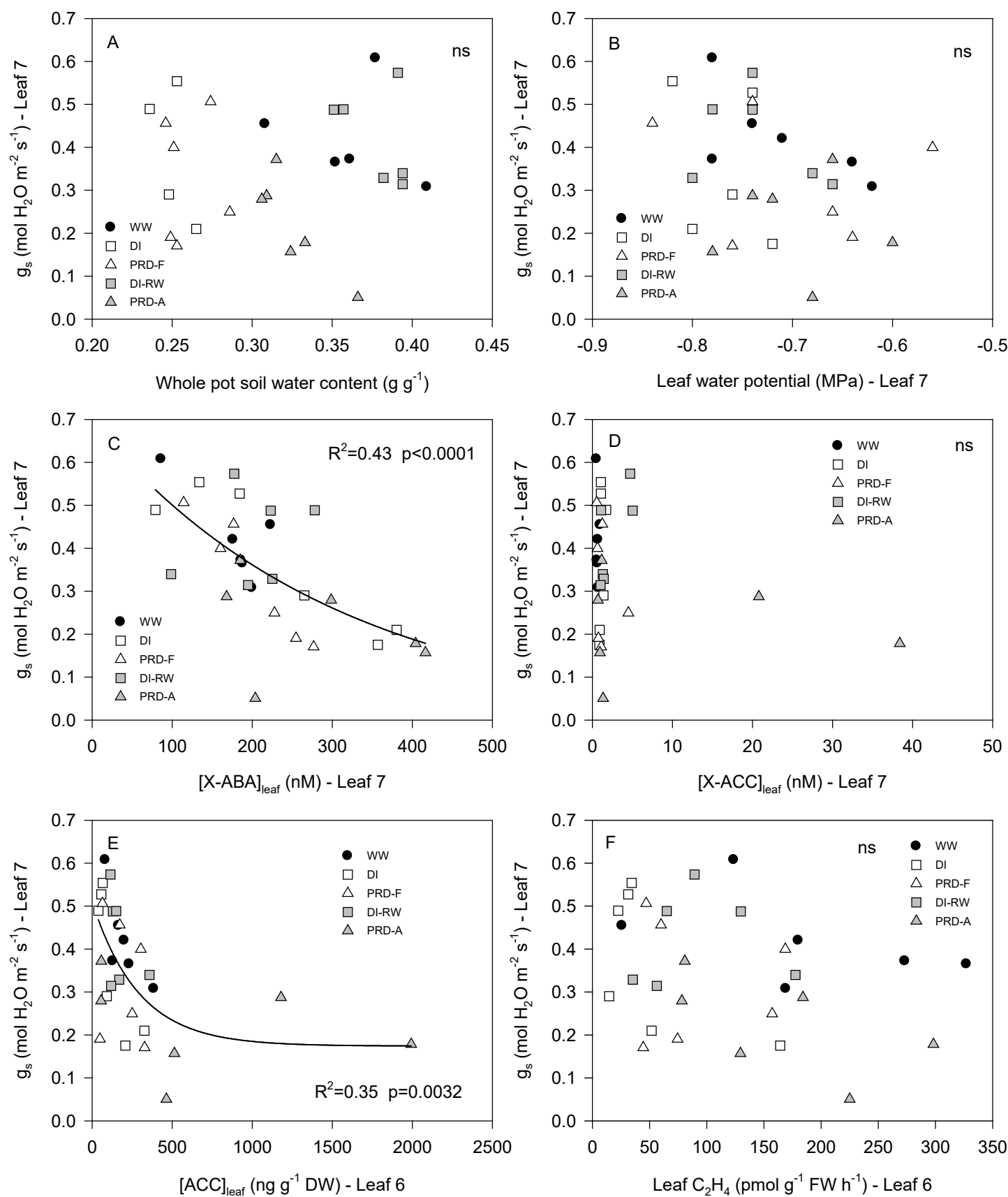

Figure 8. Relationships between stomatal conductance $\left(g_{s}\right)$ and whole pot soil water content (A), leaf water potential (B), leaf xylem ABA concentration - [X-ABA $]_{\text {leaf }}(\mathrm{C})$, leaf xylem ACC concentration - $[\mathrm{X}-\mathrm{ACC}]_{\text {leaf }}(\mathrm{D})$, leaf ACC concentration - $[\mathrm{ACC}]_{\text {leaf }}$ (E) and leaf ethylene $\left(\mathrm{C}_{2} \mathrm{H}_{4}\right)$ evolution (F) for WW, DI, PRD-F, DI-RW and PRD-A plants. Each point represents a single measurement of an individual plant and regression lines were fitted where significant $(P<0.05)$. 
Supplementary Table 1. Two-way ANOVA ( $P$-values reported - bold text when $\mathrm{P}<$ 0.05 ) of the effects of re-watering and deficit irrigation treatments (excluding wellwatered plants) on physiological parameters and hormone concentrations.

\begin{tabular}{ccccc}
\hline Parameter & $\begin{array}{c}\text { Data } \\
\text { source }\end{array}$ & $\begin{array}{c}\text { Irrigation placement } \\
(\mathrm{DI} v \text { PRD) }\end{array}$ & $\begin{array}{c}\text { Re-watering } \\
\text { effect }\end{array}$ & Interaction \\
\hline$\Psi_{\text {leaf }}$ & Table 2 & 0.087 & 0.55 & 0.64 \\
Water uptake & Table 2 & $\mathbf{0 . 0 1 5}$ & $\mathbf{0 . 0 1 5}$ & 0.63 \\
$A$ & Table 2 & 0.31 & 0.55 & 0.48 \\
$g_{s}$ & Table 2 & $\mathbf{0 . 0 3 9}$ & 0.59 & 0.18 \\
$A / g_{s}$ & Table 2 & $\mathbf{0 . 0 2 5}$ & 0.23 & 0.05 \\
{$[\mathrm{X}-\mathrm{ABA}]_{\text {leaf }}$} & Fig. 5 & 0.53 & 0.57 & 0.16 \\
{$[\mathrm{ABA}]_{\text {leaf }}$} & Fig. 5 & 0.97 & 0.079 & 0.38 \\
{$[\mathrm{X}-\mathrm{ACC}]_{\text {leaf }}$} & Fig. 5 & 0.21 & 0.127 & 0.24 \\
{$[\mathrm{ACC}]_{\text {leaf }}$} & Fig. 5 & 0.072 & 0.093 & 0.15 \\
Leaf ACO activity & Fig. 5 & 0.26 & 0.25 & 0.71 \\
Leaf $\mathrm{C}_{2} \mathrm{H}_{4}$ & Fig. 5 & $\mathbf{0 . 0 4 5}$ & $\mathbf{0 . 0 4 4}$ & 0.51 \\
Leaf $\mathrm{C}_{2} \mathrm{H}_{4} / \mathrm{g}_{\mathrm{s}}$ & Fig. 6 & 0.091 & 0.15 & 0.14 \\
\hline
\end{tabular}

$\theta_{\text {pot }}$ - whole pot soil water content; $\Psi_{\text {leaf }}$ - leaf water potential; A - leaf photosynthesis; $g_{s}$ - stomatal conductance; $A / g_{s}$ - intrinsic water use efficiency; [X-ABA] leaf - leaf xylem ABA concentration; [ABA] $]_{\text {leaf }}$ - leaf ABA concentration; [X-ACC $]_{\text {leaf }}$ - leaf xylem ACC concentration; [ACC] $]_{\text {leaf }}$ - leaf ACC concentration; leaf ACC oxidase (ACO) activity; leaf $\mathrm{C}_{2} \mathrm{H}_{4}$ - leaf ethylene evolution; leaf $\mathrm{C}_{2} \mathrm{H}_{4} / \mathrm{g}_{\mathrm{s}}$ - normalized leaf ethylene. 
Supplementary Table 2. Statistical analysis of the relationships between stomatal conductance and putative regulatory variables (whole pot soil water content $\left(\theta_{\text {pot }}\right)$, leaf water potential $\left(\Psi_{\text {leaf }}\right)$, leaf xylem ABA concentration $\left([\mathrm{X}-\mathrm{ABA}]_{\text {leaf }}\right)$, leaf xylem ACC concentration ([X-ACC $]_{\text {leaf}}$ ), leaf ABA concentration ([ABA $]_{\text {leaf }}$ ), leaf ACC concentration ([ACC $]_{\text {leaf }}$ ), leaf ethylene $\left(\mathrm{C}_{2} \mathrm{H}_{4}\right)$ evolution, $[\mathrm{X}-\mathrm{ABA}]_{\text {leaf }} /[\mathrm{X}-\mathrm{ACC}]_{\text {leaf }}$ ratio and $[\mathrm{ABA}]_{\text {leaf }} /[\mathrm{ACC}]$ leaf ratio).

\begin{tabular}{|c|c|c|c|c|}
\hline$x$-Variable & $\begin{array}{c}\text { Data } \\
\text { source }\end{array}$ & $\mathrm{R}^{2}$ & $P$-value & Type of curve \\
\hline$\theta_{\text {pot }}$ & Fig. 8A & \multicolumn{3}{|c|}{ Non-correlated } \\
\hline$\Psi_{\text {leaf }}$ & Fig. $8 \mathrm{~B}$ & \multicolumn{3}{|c|}{ Non-correlated } \\
\hline$[\mathrm{X}-\mathrm{ABA}]_{\text {leaf }}$ & Fig. $8 \mathrm{C}$ & 0.43 & $<0.0001$ & Exponential decay \\
\hline$[\mathrm{X}-\mathrm{ACC}]_{\text {leaf }}$ & Fig. 8D & \multicolumn{3}{|c|}{ Non-correlated } \\
\hline$[\mathrm{ABA}]_{\text {leaf }}$ & Not-shown & \multicolumn{3}{|c|}{ Non-correlated } \\
\hline$[\mathrm{ACC}]_{\text {leaf }}$ & Fig. 8E & 0.35 & 0.003 & Exponential decay \\
\hline Leaf $\mathrm{C}_{2} \mathrm{H}_{4}$ & Fig. $8 \mathrm{~F}$ & 0.10 & 0.088 & Exponential decay \\
\hline$[\mathrm{X}-\mathrm{ABA}]_{\text {leaf }} /[\mathrm{X}-\mathrm{ACC}]_{\text {leaf }}$ & Not-shown & 0.24 & 0.034 & Polynomial second order \\
\hline$[\mathrm{ABA}]_{\text {lea }} /[\mathrm{ACC}]_{\text {leaf }}$ & Not-shown & 0.35 & 0.003 & Polynomial inverse $2^{\text {nd }}$ order \\
\hline
\end{tabular}




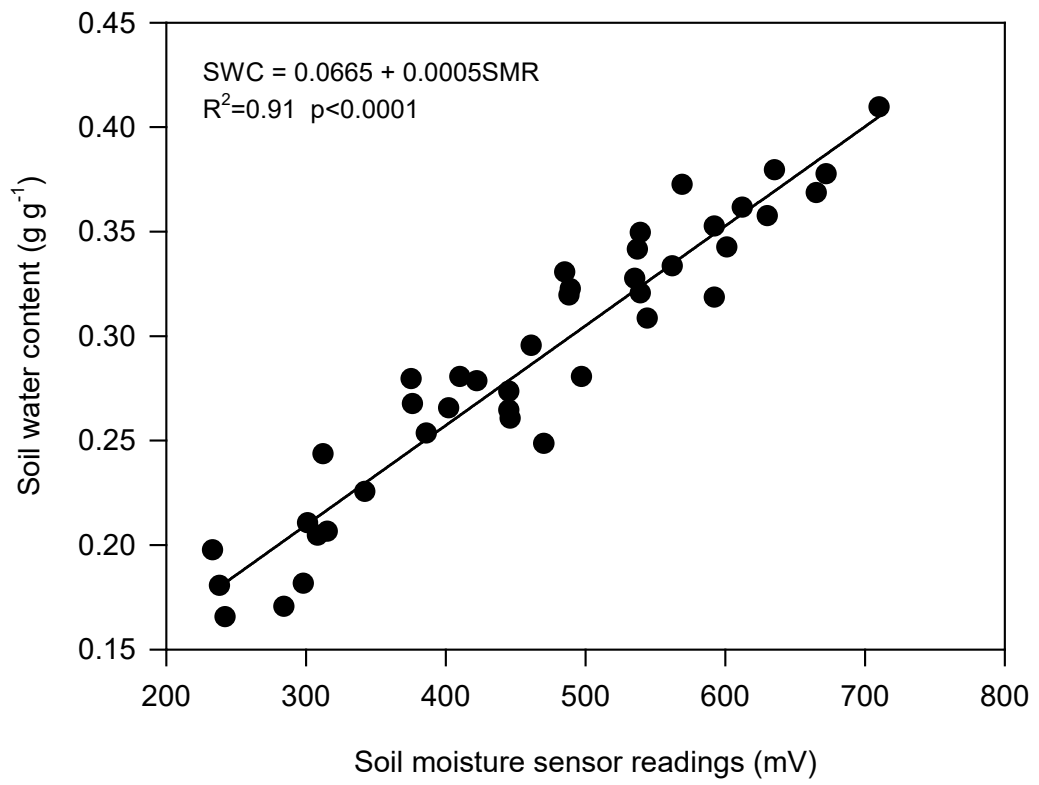

Supplementary Figure 1. Calibration of gravimetric soil water content using ML2X Delta-T soil moisture sensors. Each point is a paired measurement. 